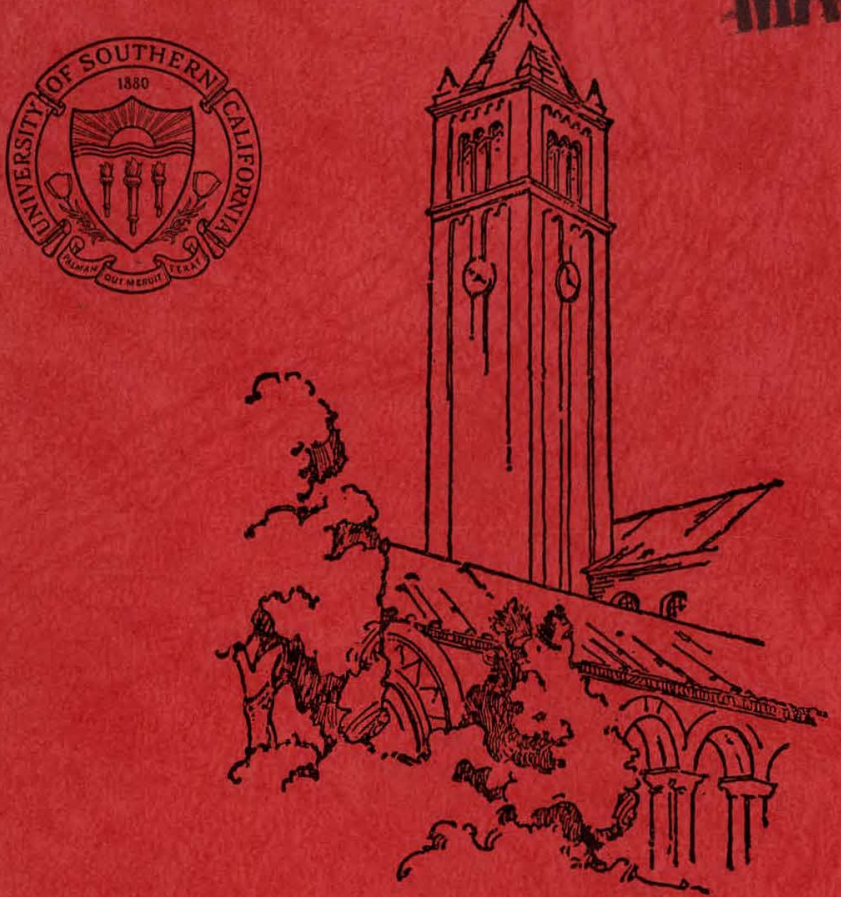

\title{
DEPARTMENT OF PHYSICS
}

University of Southern California

Los Angeles, California 90007 


\section{DISCLAIMER}

This report was prepared as an account of work sponsored by an agency of the United States Government. Neither the United States Government nor any agency Thereof, nor any of their employees, makes any warranty, express or implied, or assumes any legal liability or responsibility for the accuracy, completeness, or usefulness of any information, apparatus, product, or process disclosed, or represents that its use would not infringe privately owned rights. Reference herein to any specific commercial product, process, or service by trade name, trademark, manufacturer, or otherwise does not necessarily constitute or imply its endorsement, recommendation, or favoring by the United States Government or any agency thereof. The views and opinions of authors expressed herein do not necessarily state or reflect those of the United States Government or any agency thereof. 


\section{DISCLAIMER}

Portions of this document may be illegible in electronic image products. Images are produced from the best available original document. 


\section{Master}

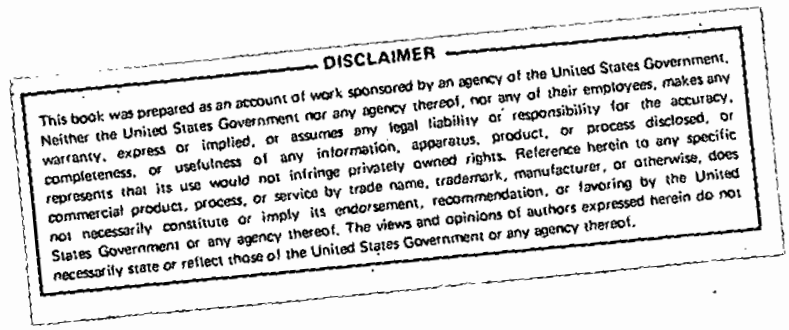

Annual Progress Report

of the

U.S.C. Nuclear Phys1cs Research Iaboratory

supported by

U. S. Atomic thergy Commission

Contract AT $(04-3)-136$

AtO3. 76 ER 70026

October 1965

Department of Physics

University of Southern California

Los Angeles, California 90007 
CHAPTER

PAGE

INTRODUCTION

A. ACCELERATOR PROGRESS

1. Operation ....................... 1

2. Machine Improvements . . . . . . . . . . . . 2

B. EXPERIMENTAL PROGRaM ... . . . . . . . . . . . . . 4

1. Angular Correlation of Colncident Charged Particles - 4

a) $\mathrm{Li}^{7}(\mathrm{p}, \mathrm{pd}) \mathrm{He}^{5}$ and $\mathrm{Li}{ }^{7}(\mathrm{p}, 2 \mathrm{p}) \mathrm{He}^{6}$ at $30 \mathrm{MeV}$. . . . 4

b) $\mathrm{He}^{3}(\mathrm{p}, \mathrm{pd}) \mathrm{p}$ at $30 \mathrm{MeV} . . . \cdot . \cdot . \cdot . \cdot . \cdot 9$

2. P1ckup Reactions ................ . 13

a) Pickup Reactions on $\mathrm{LI}^{7}$. . . . . . . . . 13

b) Siudy of the $\mathrm{F}^{19}$ Nucleus . . . . . . . . . 19

c) The $\mathrm{He}^{3}(\mathrm{p}, \mathrm{d}) 2 \mathrm{p}$ Reaction at $30 \mathrm{MeV} \cdot{ }^{\circ} 22$

3. Proton Elastic and Inelastic Scattering . . . . . 26

a) Elastic and Inelastic Scattering of $28 \mathrm{MeV}$ Protons 26

b) Elast1c and Inelast1c Scattering of $30 \mathrm{MeV}$ Protons

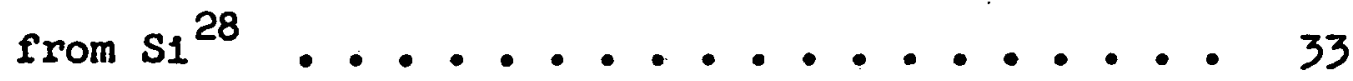

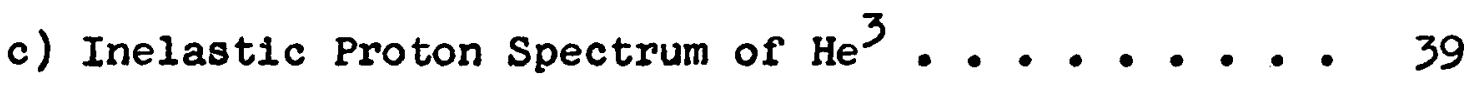

4. Proton Total Keàction Cross Sections . . . . . . . 41

a) Proton Total Reaction Cross Sections at $28 \mathrm{MeV}$. 41

b) Carbon Total Reaction Cross Sections for Proton

Energies between $16-28 \mathrm{MeV}$. . . . . . . 48

c) Study of Beryllium between 16 and $28 \mathrm{MeV}$. . . . 53

5. Penetration of Charged Particles in Matter . . - 55

a) Proton Stopping Power Measurements in Several

Elements . . . . . . . . . . . . 55

b) Calculations of Shell Corrections . . . . . . 61 
C. THEORETICAL PROGRAM . . . . . . . . . . . . . 62

1. Nucleon-Nucleon Scattering from One-Boson Exchange Potentials ..................... 62

2. Effect of Ant18ymmetrization on Stripping Reactions using Distorted Waves ............... 63

3. Analyt1c Expressions for the Born Approximation to Certain Elements of the Reactance Matrix in $\mathrm{e}^{-}-\mathrm{H}$ scattering .. . . . . . . . . . . . 64

4. Classical and Quantum Theory of Spln . . . . . . 65 APPENDIX . . . . . . . . . . . . . . . . . . 67

1. Nuclear Physics Staff . . . . . . . . . . . 68

2. U.S.C. LInac Publications .............. 71 


\section{INTRODUCTION}

This Report covers the activities of the Nuclear Physics Laboratory of the University of Southern California for the period oct. 1, 1964 - Sept. 30, 1965. During this period, research has continued to center around the $31 \mathrm{MeV}$ Proton Linear Accelerator, with particular emphasis on reactions resulting in more than two fragments, and on absolute determinations of total reaction cross sections. Research at the Laboratory is carried on by faculty, associates and students of the Physics Department of the University. Support for the program is provided by the University of Southern California and the U.S. Atomic Energy Commission.

In May, 2965, Professor G. L. Weissler resigned from the position of Chief Investigator on AEC Contract AT(04-3) 136, which he had held since the Linear Accelerator was transferred to U.S.C. from Berkeley in 1958, in order to concentrate h1s activities on his researches in electronic, atomic and molecular physics; and vacuum ultraviolet spectroscopy. Professor M.H.L. Pryce, who joined the UnIversity as Chairman of the Physics Department in July 1964, replaces Professor Weissler as Chief Investigator. Professors H. H. Forster and C. N. Waddell are acting as Deputy Chief Investigators.

It is appropriate at this point to pay tribute to the many and arduous services rendered by Professor Weissler to the direction of the research program on the Linear Accelerator. Particularly in the early stages, his grasp and competence in the engineering aspects of physics, in addition to his great ability as an experimentalist and an organizer of research, were invaluable to the progress of the project. 
Professor Pryce is a theoretical physicist whose associations with nuclear research laboratorles go back to 1939, when he worked in Chadwick's laboratory in Liverpool. During 1944-45 he worked with the British Atomic Energy Research team in Montreal (whlch later developed into the Chalk R1ver Laboratories and Plant) on reactor design. Since that time until 1964 he was Consultant at A.E.R.E., Harwell, and for some time acted as Head of the Theoretical Division there. His publications in nuclear physics have centered around the nuclear shell model applied to elements in the neighborhood of $\mathrm{Pb}$ 200. From 1954 unt1l 1964 he was Head of the Physics Department and Director of the H. H. Wills Physics Laboratory at the University of Bristol in England.

In addition to the physical research and machine development reported on in more detail in the body of this Report, attention has been directed towards formulating plans for future developments in nuclear physics at the University of Southern California, bearing in mind that a Linear Accelerator is no longer the most Intense source of protons avallable in the $30 \mathrm{MeV}$ region. These deliberations have not yet reached such a stage, however, that they can profitably be reported on in detail here.

THE READER IS WARNED THAT THE RESULTS REPORTED HEREIN ARE TENTATIVE AND SUBJECT TO MODIFICATION PRIOR TO FINAL PUBLICATION. 


\section{A. ACCEIERATOR PROGRESS}

1. Operation

During the last year the operation of the Linear Accelerator has followed the pattern established in previous years: the machine was operated on a 5 days per. week basis during the hours from 7:00 A.M. to 12:00 m1dnight. In addition, at the request of the experimentors, the Linac was operated up to four times per week during the hours from midnight to 7:00 A.M. WIth techniclans and research students alternating in running the machine. Weekends were used for setting up new experiments and, occasionaliy, for the bombardment of targets requested by outside research laboratories.

The division of Linear Accelerator time among various activities is shown in the following table, where it has to be remembered that part of the time listed under the heading of scheduled repairs and modifications was used for the testing of the small Linac described in the next section.

\section{Table I}

$\begin{array}{lcc} & \text { Hours } & \% \text { TIme } \\ \text { Normal Operation } & 4018 & 75.5 \\ \text { Repairs and Modifications } & 1145 & 21.5 \\ \begin{array}{l}\text { Bombardment for Outside } \\ \text { Investigators }\end{array} & \frac{161}{5324} & \frac{3.0}{100.00}\end{array}$




\section{Machine Improvements}

In previous proposals it has been indicated that a substantial increase in accelerator performance and reduction in malntenance time and expense would be provided by the replacement of the existing Van de Graaff infector by a $4 \mathrm{MeV}$ Linac, itself fed by a Cockcroft-Walton accelerator. At that time 1t was thought that it would be necessary to fabricate all parts of this Linac except for the drift tubes, which would be avallable as surplus 1 tems from the Lawrence Radiation Laboratory. However, because LRL no longer needed the R.F. Linac for model testing, we have obtained the entire $10 \mathrm{MeV}$ Bevatron infector as a surplus 1 tem. This forms the basis for the $4 \mathrm{MeV}$ ilnear accelerator.

During 1965, work proceeded on the modification of this Linac to produce the required $4 \mathrm{MeV}$ proton beam. An end plate was installed at the $4 \mathrm{MeV}$ position and r.f. testing of the cavity tuning system was accomplished. Initially, flat vane tuners were tested; these were then replaced with ball tuners for easier tuning operation. It was established that the tuning range was sufficlent to permit the injector to be resonated at the frequency of the tank of the main ( $31 \mathrm{MeV}$ ) Linear Accelerator. It is planned to use ball tuners for coarse adjustment and flat tuners for vernier adjustment.

It was found that a solld dielectric transmission line could not be used to transmit the required $r . f$. power from the main tank to the infector. Therefore, to fac1litate further test1ng, one of the "pre-exc1ter" osc1llators was used to exc1te the injector cavity to the required $r . f$. fleld level. 
A proton beam was accelerated with this setup, and the energy of the beam determined from the measurement of the energy of protons scattered for a gold foll. The solld state detector was calibrated with $\alpha$-particles and the mean energy of the proton beam was found to be $4.0 \mathrm{MeV}$.

A $480 \mathrm{keV}$ Cockroft-Walton injector has also been constructed. This infector utilized surplus capacitors from MURA and silicon rectifiers avallable from "state-surplus" stores. Th1s injector has been operated at voltages in excess of that required for operation, and 1t was used to provide the proton beam for the testing of the $4 \mathrm{MeV}$ Linac. Regulating c1rcuits for the Cockroft-Walton are now being constructed.

After measurement of the energy of the accelerated beam, the r.f. cavity and vacuum enclosure were cut down to length. After vacuum testing of the Linac was completed, $r . f$. power was transmitted from the tank of the main Linac using a dielectric, coaxial transmission line. No difflculty was encountered in transmitting the required r.f. power.

Beam handing components and the required regulating circults are now being constructed. It is planned to operate the injector at full beam level' in 1 ts present test position before replacing the present VaG. Injector. All of the testing has been accomplished without interfering with the normal operation schedule.

We gratefully acknowledge the assistance of Dr. Bruce Cork, Ferdinand Voelker and William Eaton of the Lawrence Radiation Laboratory. 


\section{B. EXPERIMENTAL PROGRAM}

\section{Angular Correlation of Colncident Charged Particles}
a)
$\mathrm{Li}^{7}(\mathrm{p}, \mathrm{pd}) \mathrm{He}^{5}$ and $\mathrm{Li}^{7}(\mathrm{p}, 2 \mathrm{p}) \mathrm{He}^{6}$ at $30 \mathrm{MeV}$ (D. W. Devins and H. H. Forster)

The study of the angular correlation of coincident charged particles emitted from light nuclei under proton bombardment, which was started last year with the $\mathrm{LI}^{6}(\mathrm{p}, \mathrm{pd}) \mathrm{He}^{4}$ reaction, was continued. The experimental setup was similar to that used for the investigation of $\mathrm{Li}^{6}(\mathrm{p}, \mathrm{pd}) \mathrm{He}^{4}$. $^{(1)}$ Particles were identified in a $\mathrm{dE} / \mathrm{dx}-\mathrm{E}$ counter telescope placed on a movable arm at an angle $\theta$ with respect to the incident beam, and colncident charged particles were detected in an $E$ counter placed symmetrically on a second detector arm. A fast-slow coincidence system in confunction w1th a two dimensional analyzer ${ }^{(2)}$ was used for the analysis of the data. Fig. I is a block diagram of the electronics used; fig, 2 represents the experimental results for the $\mathrm{LI}^{7}(\mathrm{p}, \mathrm{pd}) \mathrm{He}^{5}$ angular distribution at laboratory angles ranging from $20^{\circ}-75^{\circ}$. For comparison the experimental results obtained previously for the $L 1^{6}(p, p d) \mathrm{He}^{4}$ reaction are included in the same figure. The two angular correlations are clearly very different. In the case of $\mathrm{LI}^{6}$ the angular distribution could be expla1ned in terms of a cluster structure $\alpha+d$, with the maximum in the correlation occurring at approximately the free p-d scattering angle. A similar interpretation for $\mathrm{LI}^{7}$ where the ground state of $\mathrm{LI}^{7}$ could be thought of as $\mathrm{d}+\mathrm{He}^{5}$. would lead to a peak in the angular 


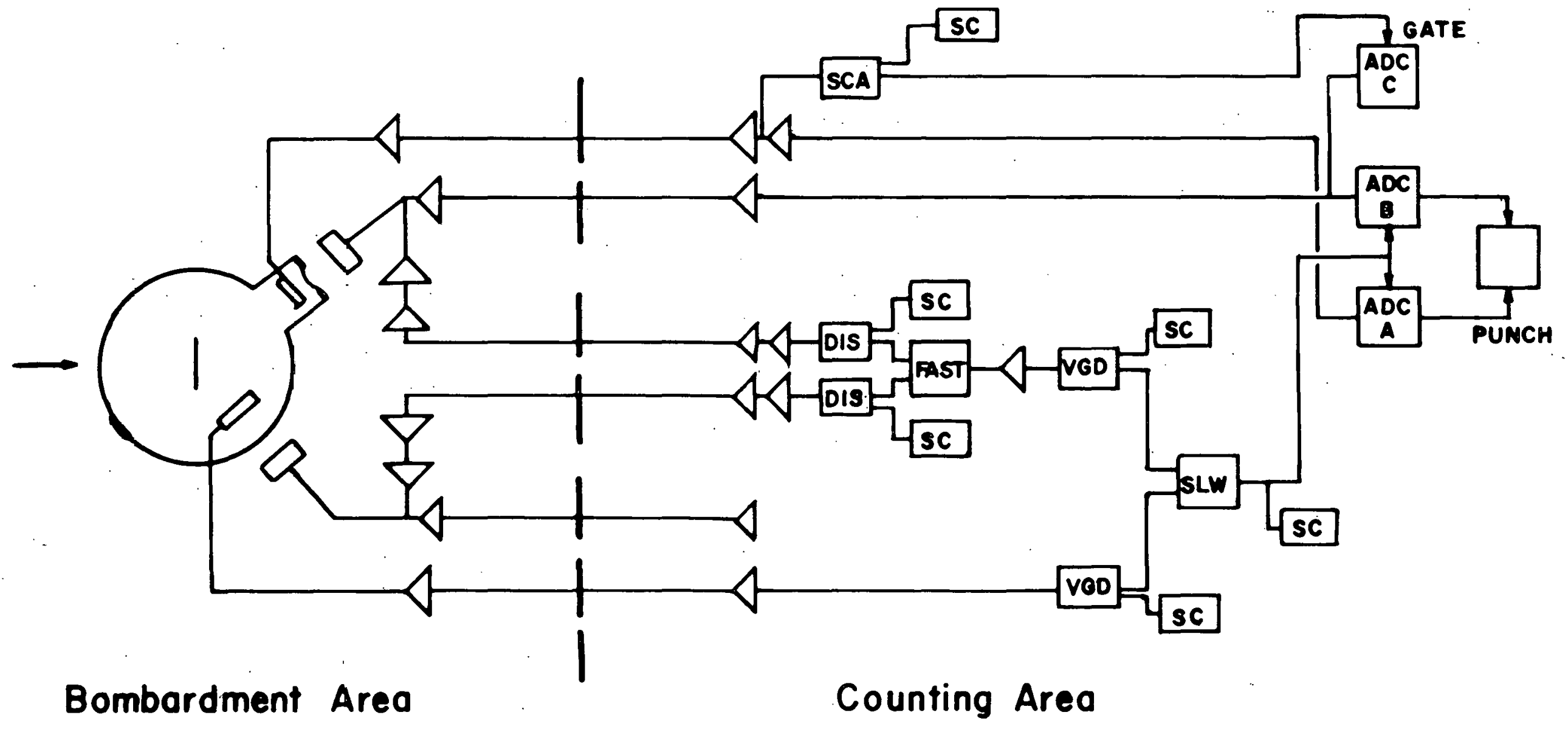

F1gure 1 


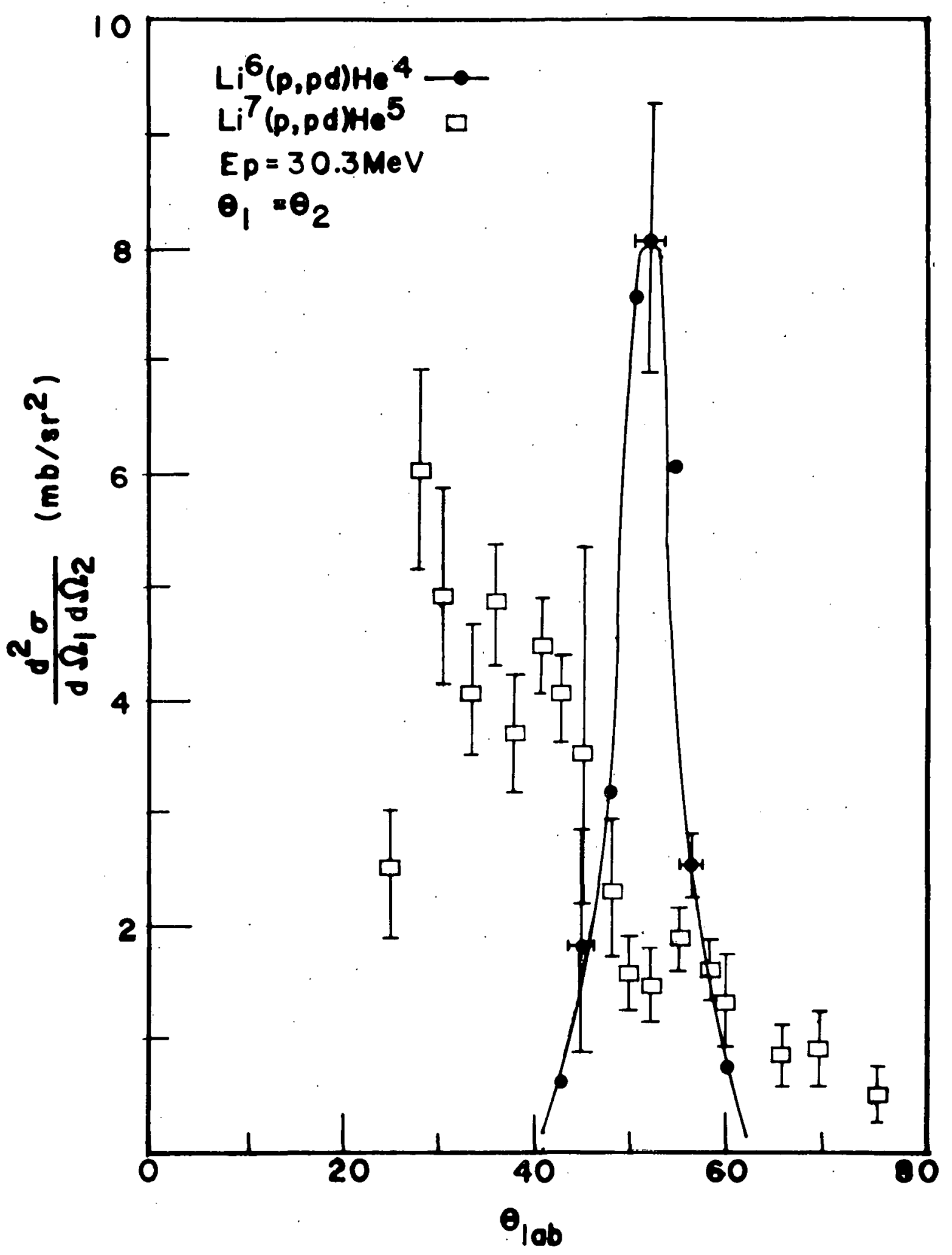

Figure 2 
correlation at a laboratory angle of $-42.5^{\circ}$. However, the angular distribution undoubtedly contains contributions from the low lying excited states in $\mathrm{He}^{5}$ and from 3 or 4 body break up of $L^{7}$, whlch makes the results more difficult to interpret.

Preliminary data obtained for the $\mathrm{Li}^{7}(p, 2 \mathrm{p}) \mathrm{He}^{6}$ reaction are plotted in fig. 3 as a function of the laboratory angle $\theta$. At higher bombarding energies $(150$ - $340 \mathrm{MeV})(p, 2 p)$ experiments have led to a considerable amount of information regarding the individual states of protons in nuclei. (3) At $30 \mathrm{MeV}$ the interaction will be localized in the nuclear surface and hence should lead to a different kind of information. The angular correlation differs markedly from that obtalned at higher proton bombarding energies for light nucle1; it shows a rapid rise in the cross section at small angles and an osc11lating pattern at angles $\theta>35^{\circ}$, possibly due to diffraction effects in the nuclear surface. A similar type of structure has recently been obtalned in a study of the reaction $C^{12}(p, 2 p) B^{\prime \prime}$ at $50 \mathrm{MeV} .{ }^{(4)}$

It is planned to continue the experiment and to fit the data with a distorted wave Born analysis calculation.

(I) D. W. Devins, H. H. Forster, S. M. Bunch and C. C. KIm, Phys. Letters 9, 35 (1964).

${ }^{(2)}$ C. N. Waddell, E. L. Cohn, and T. K. Inman, Bull. Am. Phys. Soc. 8, 596 (1963).

(3) For a summary, see, e.g.: M. Riou, Revs. of Modern Physics 37 (1965) 375. (4) H. G. Pugh, D. L. : Hendrie, Marc Chabre, and E. Bosch1tz, Phys. Rev. Letters 14 (1965) 434. 


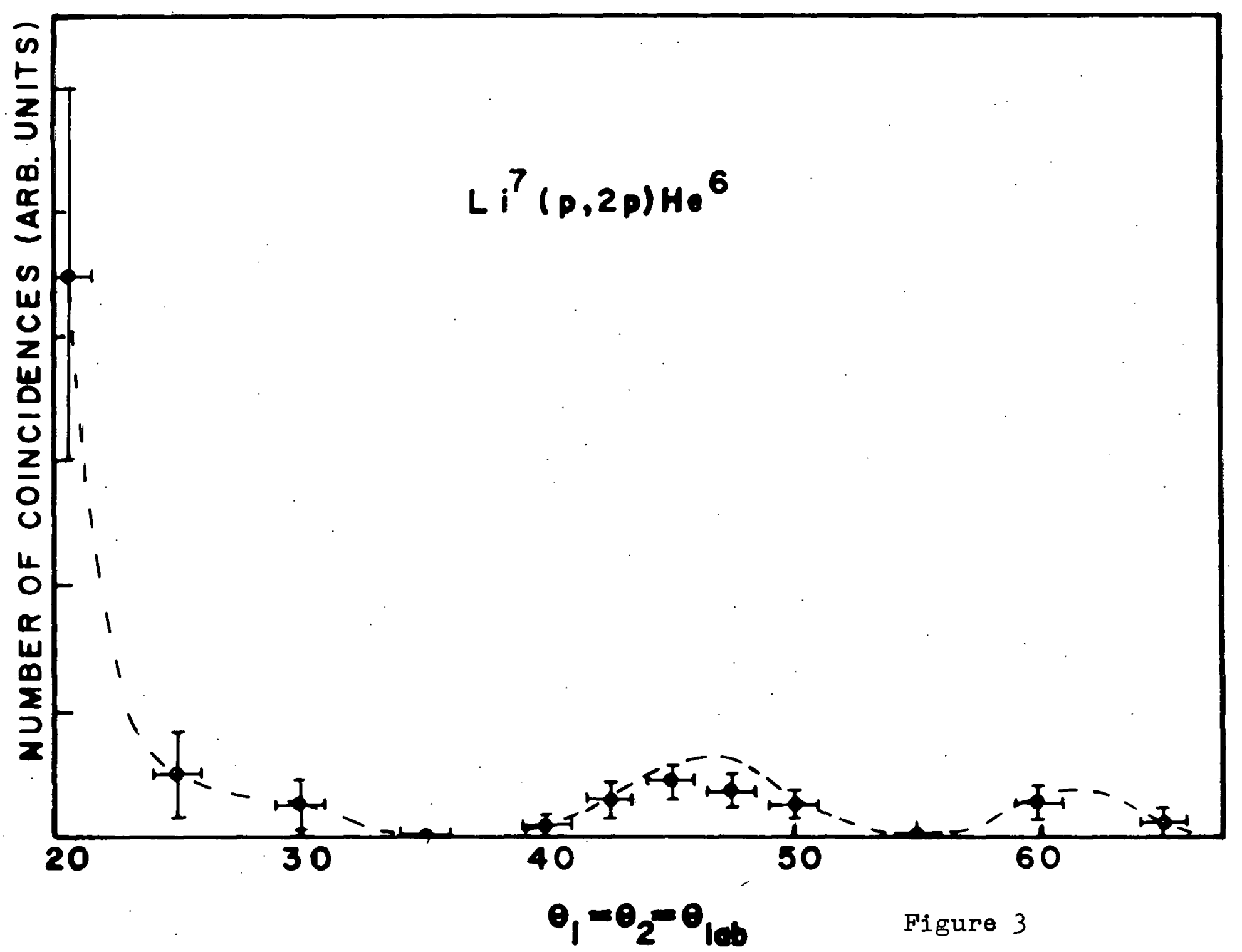


b) $\mathrm{He}^{3}(p, p d)$ at $30 \mathrm{MeV}$ (C. C. Kim, S. M. Bunch, and H. H. Forster)

The arrangement for this experiment was in principle similar to that described for the $\mathrm{Li}^{7}(\mathrm{p}, \mathrm{pd}) \mathrm{H} \mathrm{H}^{5}$ reaction. However, there were some differences. The gaseous target $\left(99.8 \%\right.$ pure $\left.\mathrm{He}^{3}+.19 \% \mathrm{He}^{4}\right)$ was contained in a small scattering chamber which, in turn, was placed inside a larger evacuated chamber described elsewhere. (1) The scattering arm containing the $\frac{\mathrm{dE}}{\mathrm{dx}}-\mathrm{E}$ counter telescope was held at a fixed angle, while the angle of the other arm containing the second $\mathrm{E}$ detector was varied from $\theta_{\mathrm{Lab}} \sim 25^{\circ}$ to $\theta_{\text {Lab }} \sim 95^{\circ}$. The electronics was similar to the one described above: the output signals of the two $E$ detectors were put in fast coincldence and provided a gate for the $2 D$ analyzer. Energy calibration and $E$ vs. $\Delta E$ calibration curves were obtained with a deuterated polyethylene target and checked frequently during each run.

Figs. 4 and 5 represent the experimental data for the $\mathrm{He}^{3}(p, p d) \mathrm{H}^{l}$ reaction; differential cross sections are plotted versus laboratory angles; the deuteron identification was made in the fixed arm, held at $\theta=30^{\circ}$ and $\theta=40^{\circ}$, respectively. All deuterons with an energy above $5 \mathrm{MeV}$ were accepted for coincidences. The angular correlations obtained show some oscillatory structure; of particular interest is the peaking at the larger angles. Preliminary analyses based on kinematical considerations only seem to indicate that the peaking occurs at angles corresponding: 1) to quasi elastic p-d scattering, leaving the remaining 


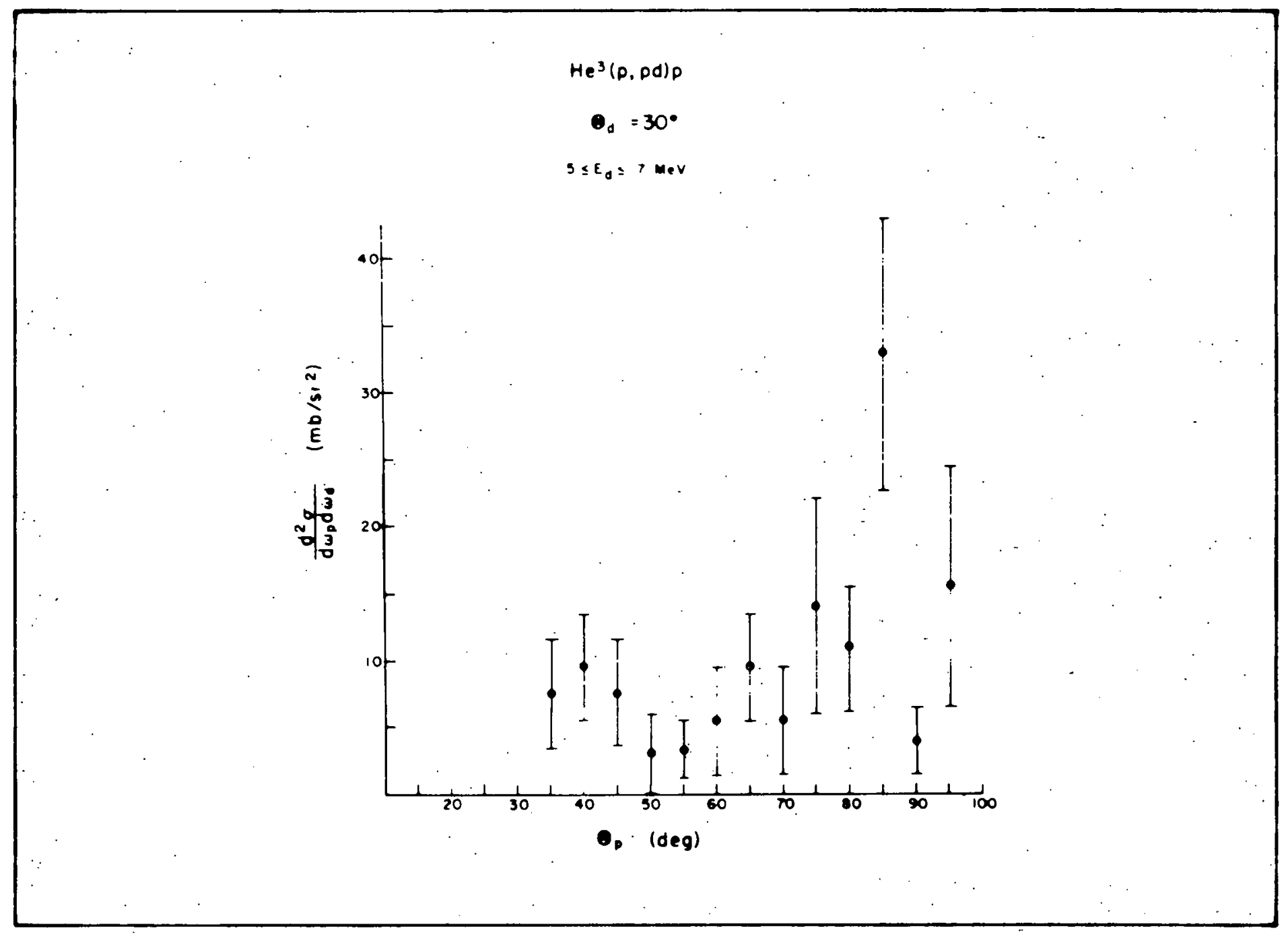

Figure 4 


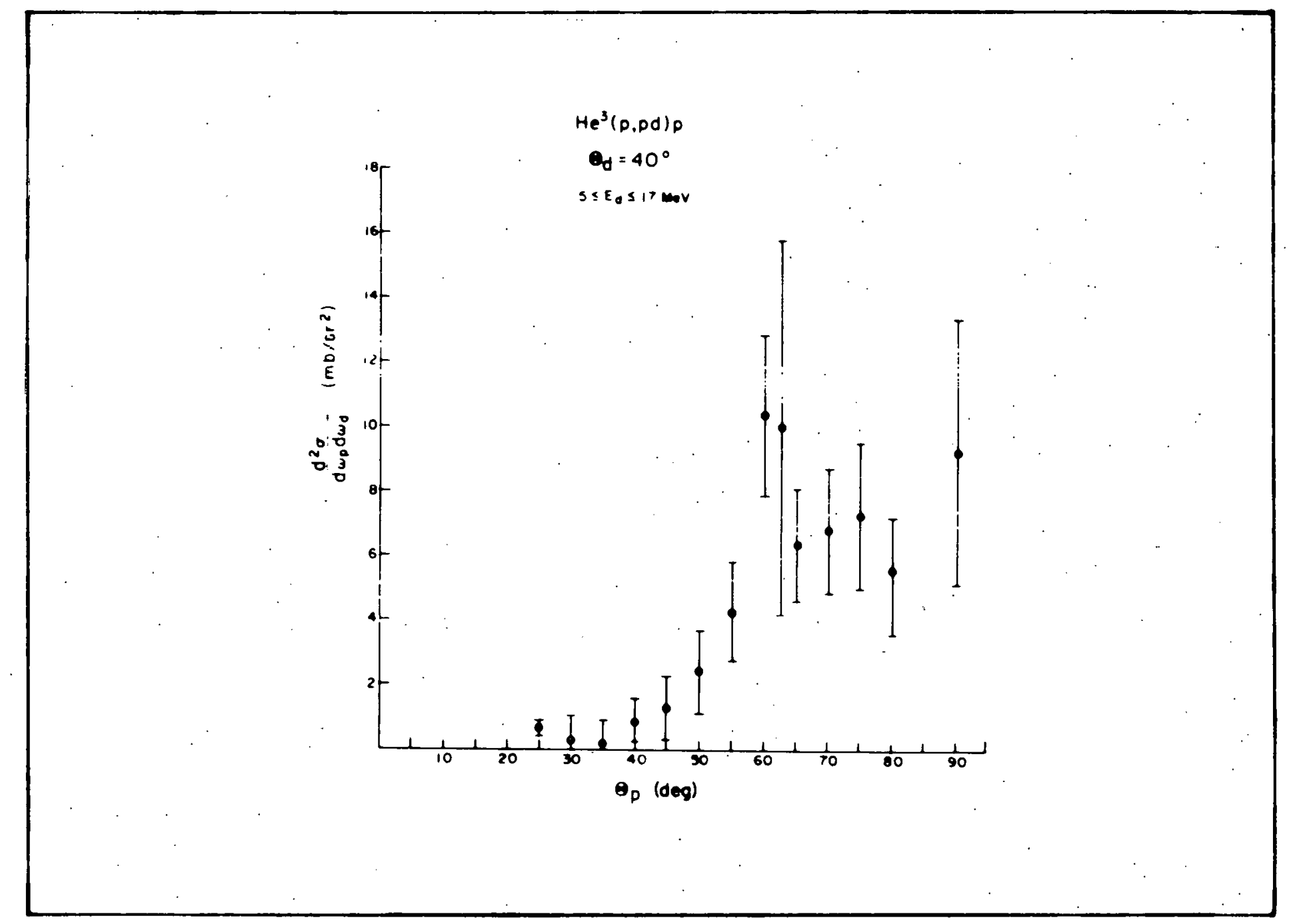

Figure 5 
proton essentially at rest, and 2) to deuterons in coincidence with two protons emitted from the nucleus with very small relative momentum. It is planned to repeat this experiment when a 4-dimensional analyzing system will be in operation.

(I) C. C. KIm, S. M. Bunoh, D. W. Devins and H. H. Forster, Nuclear Physics, Vol. 58 (1964) 32. 
2. Pickup Reactions

a) Pickup Reactions on $\mathrm{LI}^{7}$ (D.W. Devins, C. C. Kim, and H. H. Forster)

The differential cross sections $\operatorname{for}^{\prime} L 1^{7}(p, d) L 1^{6}$ and $L_{1}^{7}(p, t) L 1^{5}$ reactions have been studied using a $\frac{d E}{d x}-E$ counter telescope. Slow coincldences between the two detectors gated the two dimensional analyzing system described above. Data were accumulated on punch tape and a computer program set up to read the tape. (1) Angular distributions were obtained for the $L_{1}^{7}(p, d) L_{i}{ }^{6}$ and $L 1^{7}(p, t) L L^{5}$ reactions; some preliminary data were also obtained for the $L_{i}^{7}(p, \alpha)$ and $L I^{7}\left(p, H e^{3}\right)$ reactions, but this part of the experiment is not completed and will be continued.

Typical spectra obtained for the $(p, d)$ and $(p, t)$ reactions on $\mathrm{Li}^{7}$ are shown in figs. 6 and 7 . As can be seen from fig. 6 the ground state and first two exclted states are fairly well separated. The experiment was carried out over an angular range from $\theta_{\text {Lab }} \sim 8^{\circ}$ to $\theta_{\text {Lab }} \sim 100^{\circ}$, but only contributions from the ground state were well resolved over the whole angular range; deuterons from the first excited state could not be separated accurately from the continuum at $\theta_{\mathrm{Lab}}>85^{\circ}$, nor those from the second excited state at $\theta_{\text {Lab }}>74.5^{\circ}$. Fig. 8 represents a plot of the angular distribution of the $(p, d)$ differential cross sections in the C.M. system for $Q$ - values of $-5.03 ;-7.23$; and $-8.59 \mathrm{MeV}$, respectlvely. A Butler theory calculation is at present being performed 


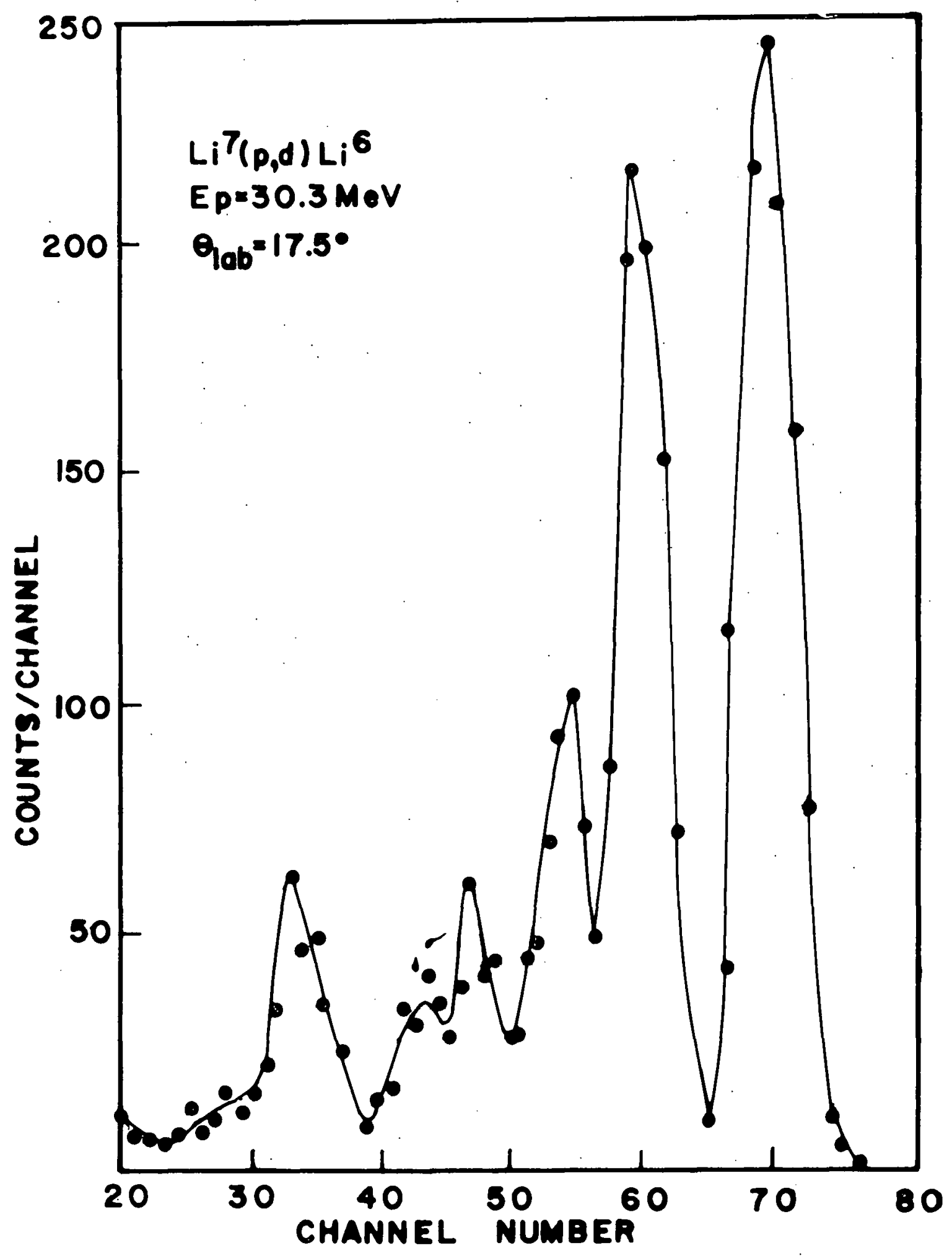

Figure 6 


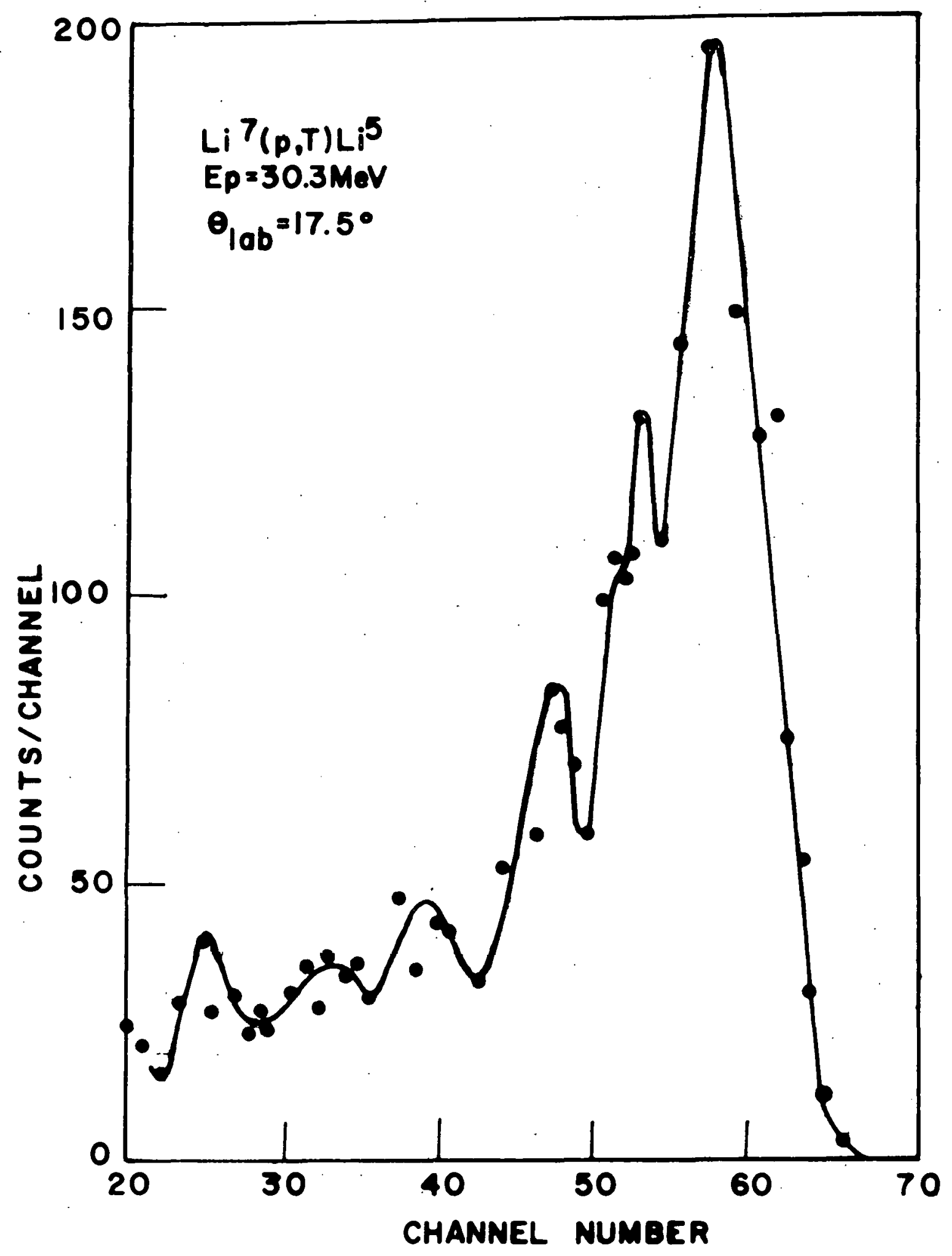

FIgure 7 
for the purpose of comparing theory with experiment. Fig. 9 is a plot of the angular distribution of the cross section for the $L_{i}^{7}(p, t) L_{i}^{5}$ reaction. In this case what is plotted is $\frac{d^{2} \sigma}{d \Omega d E}$ obtained by summing the contributions over an energy range of $\triangle \mathrm{E}=3 \mathrm{MieV}$. 


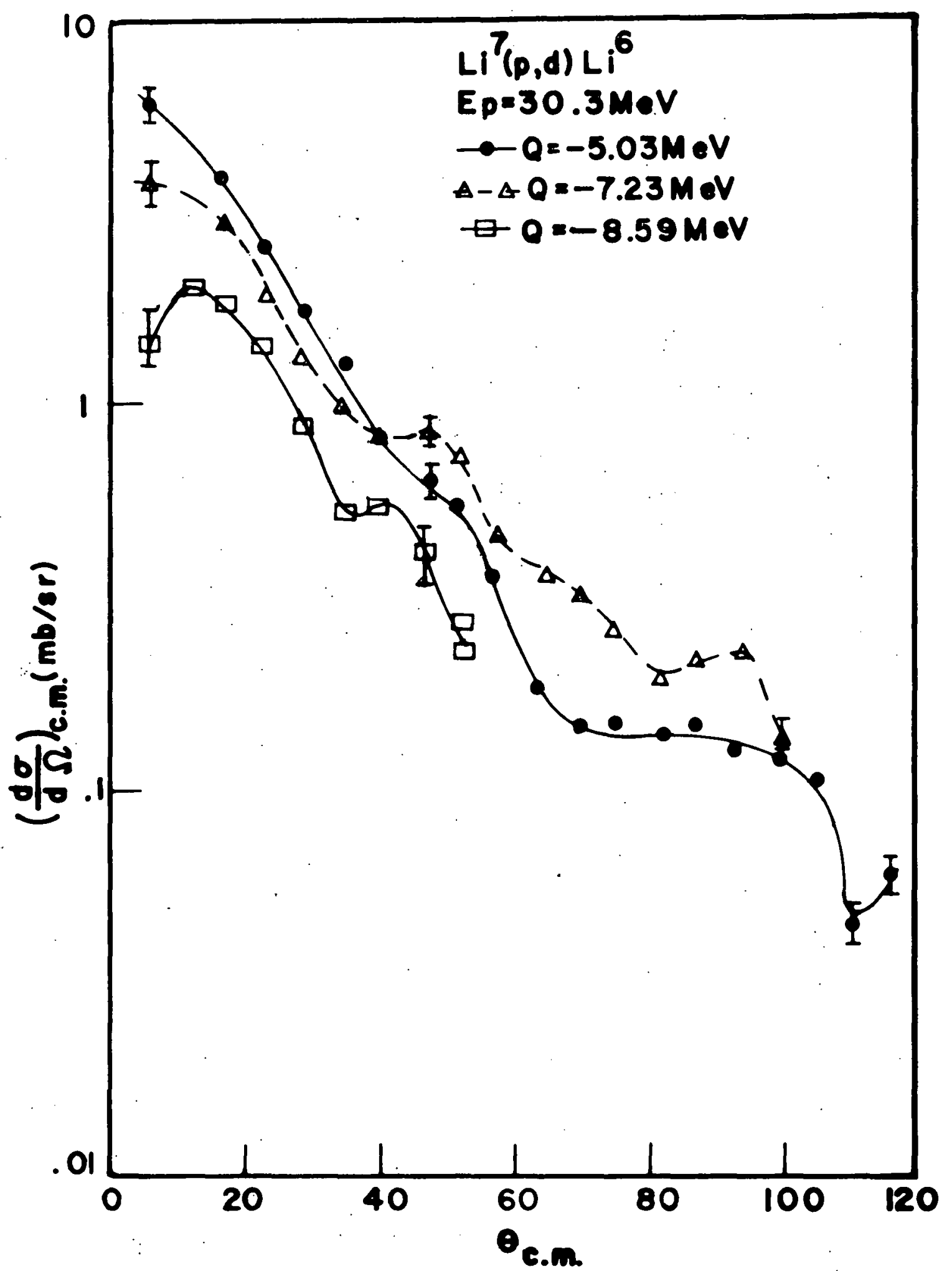

Figure 8 


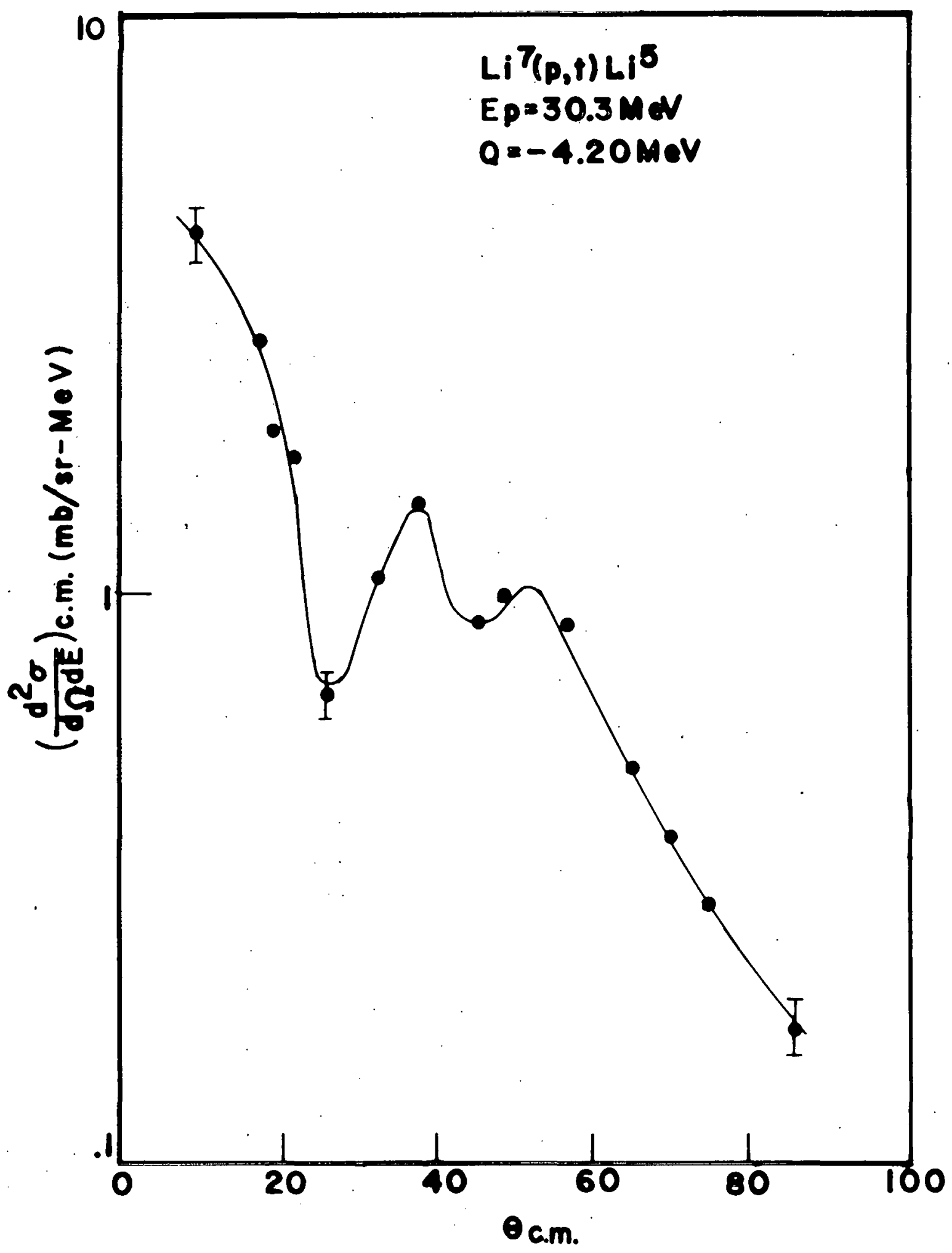

Pigure 9 
b) Study of the $F^{19}$ Nucleus (R. K. Cole, C. N. Waddell, and associates)

The $\mathrm{F}^{19}\left(\mathrm{p}, \mathrm{He}^{4}\right) \mathrm{O}^{16}$ and $\mathrm{F}^{19}\left(\mathrm{p}, \mathrm{He}^{3}\right) \mathrm{O}^{17}$ reactions have been measured as reported in the 1964 Annual Progress Report. Both angular distributions, figs. 10 and 11 , show pronounced forward peaking with the $\left(p, \mathrm{He}^{4}\right)$ cross section showing strong oscillations. The relative magnitude of the cross sections and the forward peaking of the angular distributions are consistent with the shell model description of the ground state of $F^{19}$ together with a direct pick-up mechanisin. However, a simple plane wave approximation of the direct pick-up of nucleons by the incident proton does not provide a very good fit to the experimental results. (1) A distorted wave pick-up model of both these reactions is presently being investigated by $J$. K. Dickens of Oak Ridge National Laboratory.

In order to obtain additional information on the structure of the $\mathrm{F}^{19}$ nucleus and the reaction mechanism, a study of the $\mathrm{F}^{19}\left(\mathrm{pH}^{2}\right) \mathrm{F}^{18}$ and the $\mathrm{F}^{19}\left(\mathrm{p} \mathrm{H}^{3}\right) \mathrm{F}^{17}$ reactions will be made. Colncident studies of the $\left(\mathrm{p}, \mathrm{pH}^{2}\right)$ and the $\left(\mathrm{p}, \mathrm{pH}^{3}\right)$ reactions are also planned when the neir 4 dimensional pulse helght analyzer becomes avallable.

(1) R. Dittman, Ph.D. thes1s (1965). 


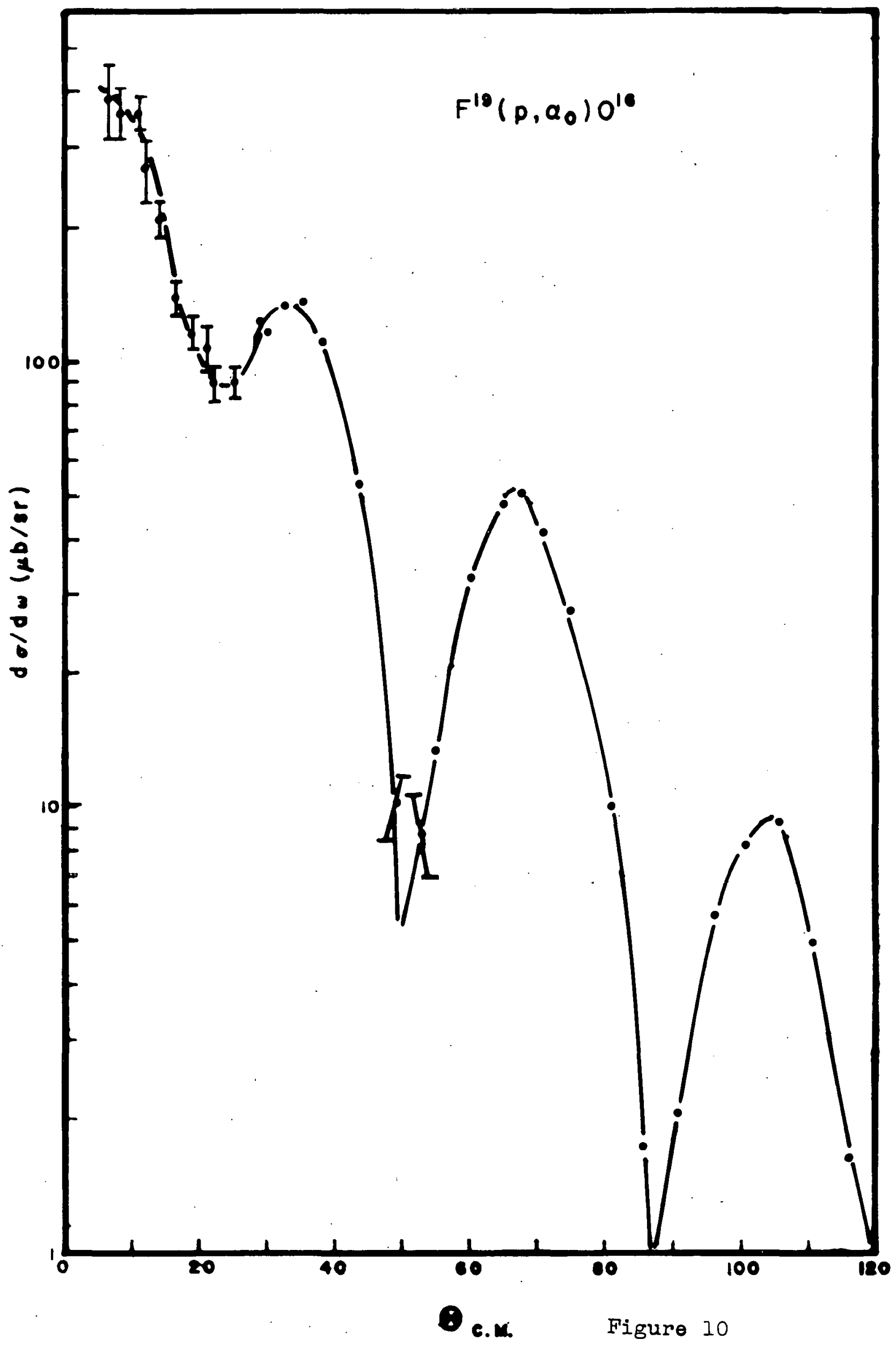




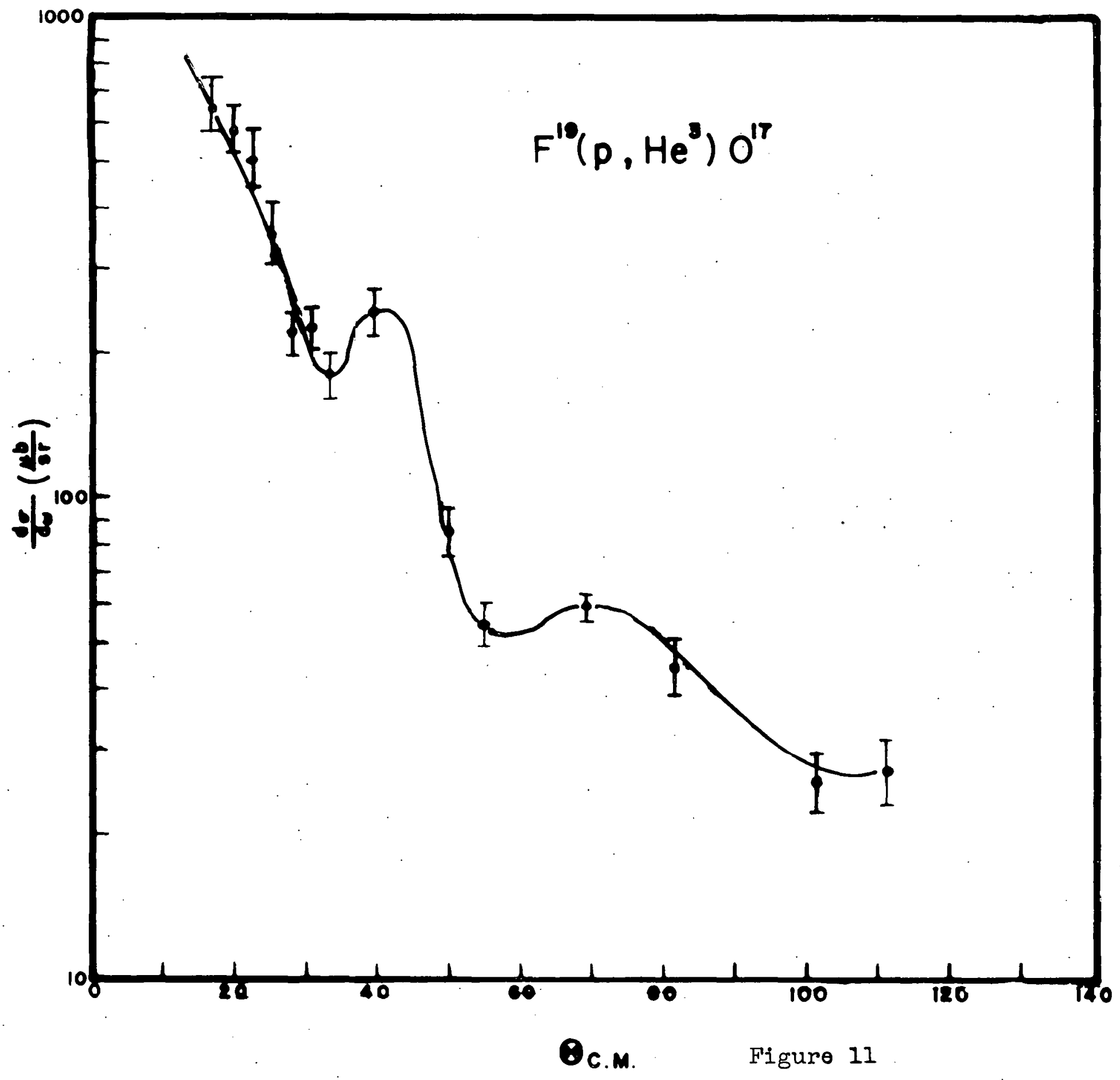


c) The $\mathrm{He}^{3}(\mathrm{p}, \mathrm{d}) 2 \mathrm{p}$ Reaction at $30 \mathrm{MeV}$ (C.C. KIm and H.H. Forster) Evidence for strong final state interaction between the two residual protons in $\mathrm{He}^{3}$ reactions has been obtained in several experiments, e.g. $\mathrm{He}^{3}(d, t) 2 p(1,2)$ at deuteron energies between 20 - $28 \mathrm{MeV} ; \mathrm{He}^{3}\left(\mathrm{He}^{3}, \alpha\right) 2 \mathrm{p}(2)$ at $\mathrm{E}_{\mathrm{He}^{3}}=26 \mathrm{MeV}$; and $\mathrm{He}^{3}(\mathrm{p}, \mathrm{d}) 2 \mathrm{p}$ at $\mathrm{E}_{\mathrm{p}}=11.94 \mathrm{MeV} \cdot{ }^{\text {(3) In this }}$ laboratory we have investigated the $\mathrm{He}^{3}(p, d) 2 p$ final state interaction at $30 \mathrm{MeV}$ proton bombarding energy.

The $\mathrm{He}^{3}$ gas $\left(99.8 \% \mathrm{He}^{3}, .19 \% \mathrm{He}^{4}, .01 \% \mathrm{H}\right)$ was contained in the small scattering chamber inside the larger evacuated scattering chamber mentioned elsewhere in this report. The scattered deuterons passed through a $.5 \mathrm{mil}$ Mylar window into a $50 \mu$ rully depleted silicon $\frac{d E}{d x}$ counter. For part of the experiment a $500 \mu$ fully depleted silicon $\frac{d E}{d x}$ counter was used. The same $\frac{d E}{d x}-E$ counter telescope described under 1 a) was used to gate the two dimensional analyzer.

Deuteron spectra were obtained with this assembly at angles ranging from $\theta_{\mathrm{Lab}}=10^{\circ}$ to $\theta_{\mathrm{Lab}}=40^{\circ}$; a typical deuteron spectrum obtained at $\theta_{\text {Lab }}=10^{\circ}$ is shown in fig.12. All spectra show the characteristic sharp cutoff corresponding to two protons going of with small relative linear momentum, but the peak in the spectrum characteristic of the final state proton-proton interaction becomes both more pronounced and narrower the smaller the angle of detection with respect to the incident proton beam. A rough comparison of the width of the spectrum under the peak with that obtained for deuterons of the same energy 


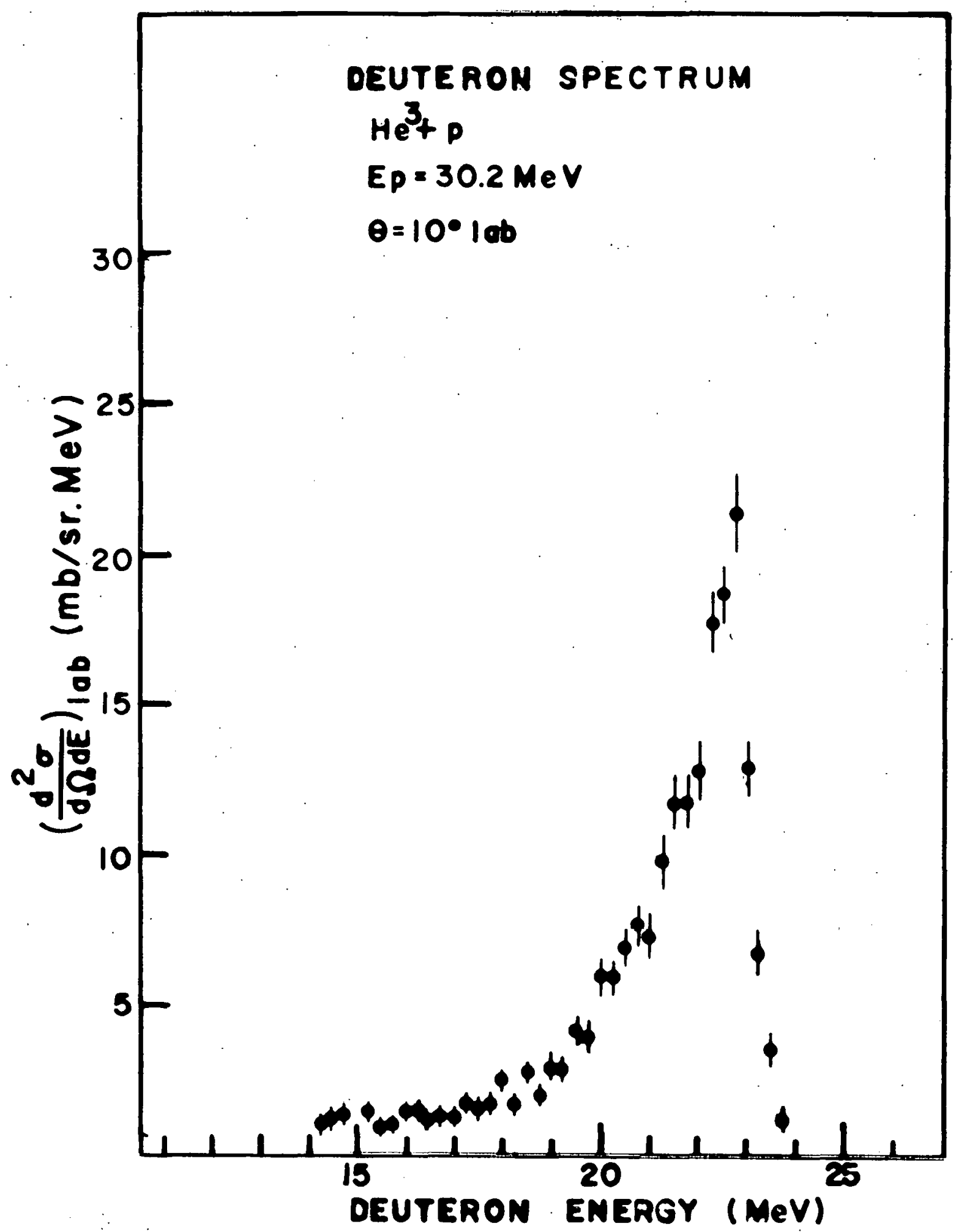

Figure 12 
in calibration muns leads to an estimate of the lifetime of the singlet diproton as $T \sim 5.10^{-22}$ sec in agreement with similar estimates made by other investigators. (1) Fig. 13 represents a plot of the differential cross section of the $\mathrm{He}^{3}(\mathrm{p}, \mathrm{d})$ 2p final state interaction at laboratory angles ranging from $\theta_{\mathrm{Lab}}=10^{\circ}$ to $\theta_{\mathrm{Lab}}=40^{\circ}$. The calculations of the cross sections have been based on the areas below the peak at the high energy end of the deuteron spectrum. However, since this peak is not completely resolved from a second one possibly corresponding to the Coulomb interaction between the particles the errors involved in the estimate of the cross sections are necessarily very large. Nevertheless, qualitatively the shape of the angular distribution of the differential cross sections can be assumed to be correct: the cross section drops rapidiy at small angles and appears to go through a minimum at $\sim 20^{\circ}$. laboratory angle. The shape of the curve is reminiscent of a pick-up reaction and a distorted wave calculation is being attempted in order to fit it.

(1) O. M. Bilaniuk ana R. J. Slobodrian, Physics Letters $I$ (1963) 77 .

${ }^{(2)_{K}}$. P. Artjomov, V. J. Chvev, V. Z. Goldberg, A. A. Ogloblin, V. P. Rudakov, J. N. Serikov, Phys. Letters 12 (1964) 53.

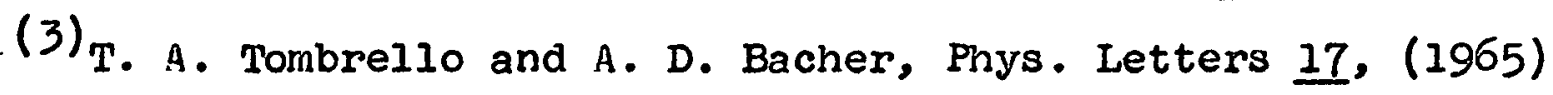
37 . 


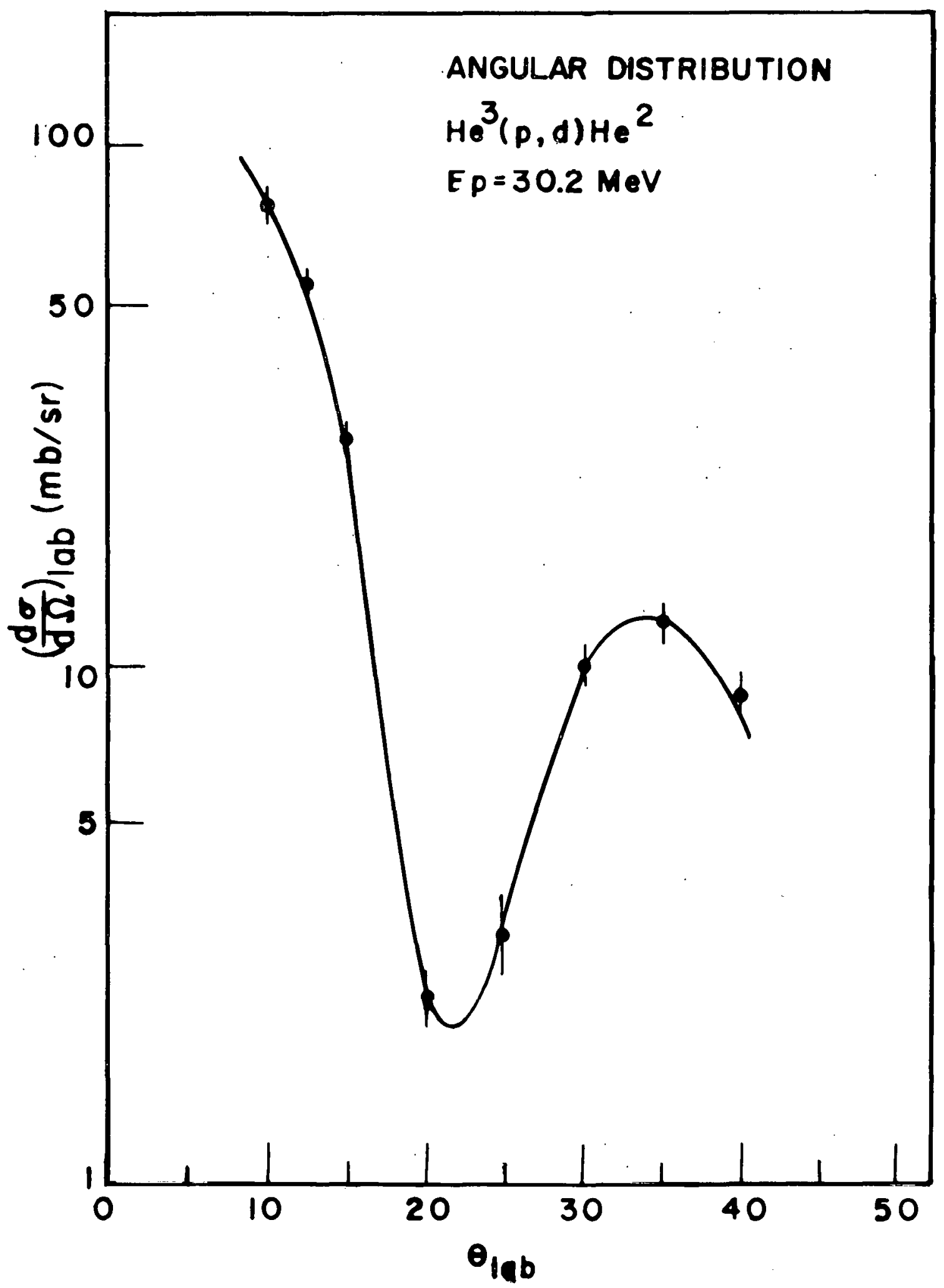

Pigure 13 
3. Proton Elastic and Inelastic Scattering

a) Elastic and Inelastic Scattering of $28 \mathrm{MeV}$ Protons (R. K. Cole, C. N. Waddell, and associates)

The experimental study of the elastic scattering of $28 \mathrm{MeV}$ protons is being continued with nuclei in the region of $\mathrm{Z}=28$, a proton closed shell. Angular distributions of protons elastically scattered by $\mathrm{Ni}$ and Co have been obtained with studies of $\mathrm{Fe}$ and $\mathrm{Zn}$ under way.

The analysis of the elastic scattering of $28 \mathrm{MeV}$ protons from $\mathrm{Al}, \mathrm{Cu}, \mathrm{Ag}$, and $\mathrm{Au}$ has been made using the diffuse-surface optical model.

$$
v_{\text {opt }}=-V(r)-i w(r)+v_{\text {couI }}(r)+V_{S O}(r)
$$

with

$$
\begin{gathered}
V(r)=V f(r)=V\left[1+\exp \frac{\left(r-R_{R}\right)}{a}\right]^{-1} \\
W(r)=W_{S} \exp \left[-\frac{\left(r-R_{I}\right)^{2}}{b^{2}}\right]+W_{V}\left\{I+\exp \left[\frac{\left(r-R_{I}\right)}{0.69 b}\right]\right\}^{-1}
\end{gathered}
$$

and

$$
v_{S O}=-v_{S}\left(\frac{h}{m_{\pi} c}\right)^{2} \frac{1}{r}\left(\frac{d f(r)}{d r}\right) \vec{\sigma} \cdot \vec{L}
$$

where for example $R_{R}=R_{O R} A^{1 / 3}$

Good fits were obtained for the $\mathrm{Al}, \mathrm{Ag}$, and $\mathrm{Au}$ angular distributions. 1 However, two possible "optimum" fits were obtalned for $\mathrm{Cu}$. This results in an ambiguity in the optlcal model parameters for $\mathrm{Cu}$. The optical model parameters obtalned in these analyses are presented in Table 2 together with the predicted and experimental total reaction sections. The experimental angular distribution with the 


\section{Table II}

$\mathrm{Cu}$

Al Branch I Branch II Ag $\mathrm{Au}$

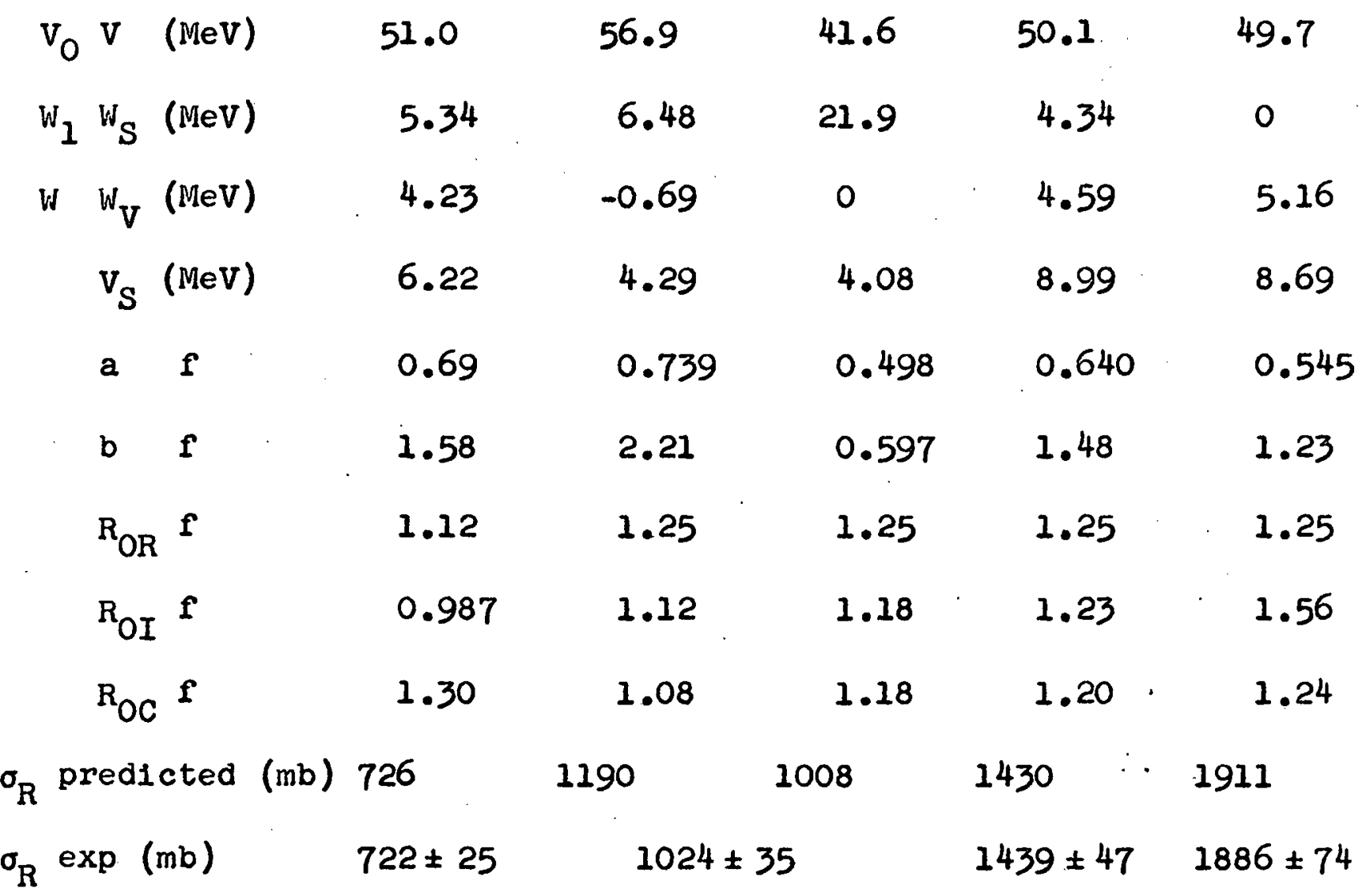


"optimum" optical model fits are given in figs. $14-17$. The differential inelastic scattering cross sections integráted over energy $A Q=-9 \mathrm{MeV}$ were also obtained for these elements. These cross sections together with the elastic scattering cross sections were used to calculate correction terms for the total reaction cross section measurements.

(1) $R$ Dittman, Thesis, University of Southern California, 1965. 


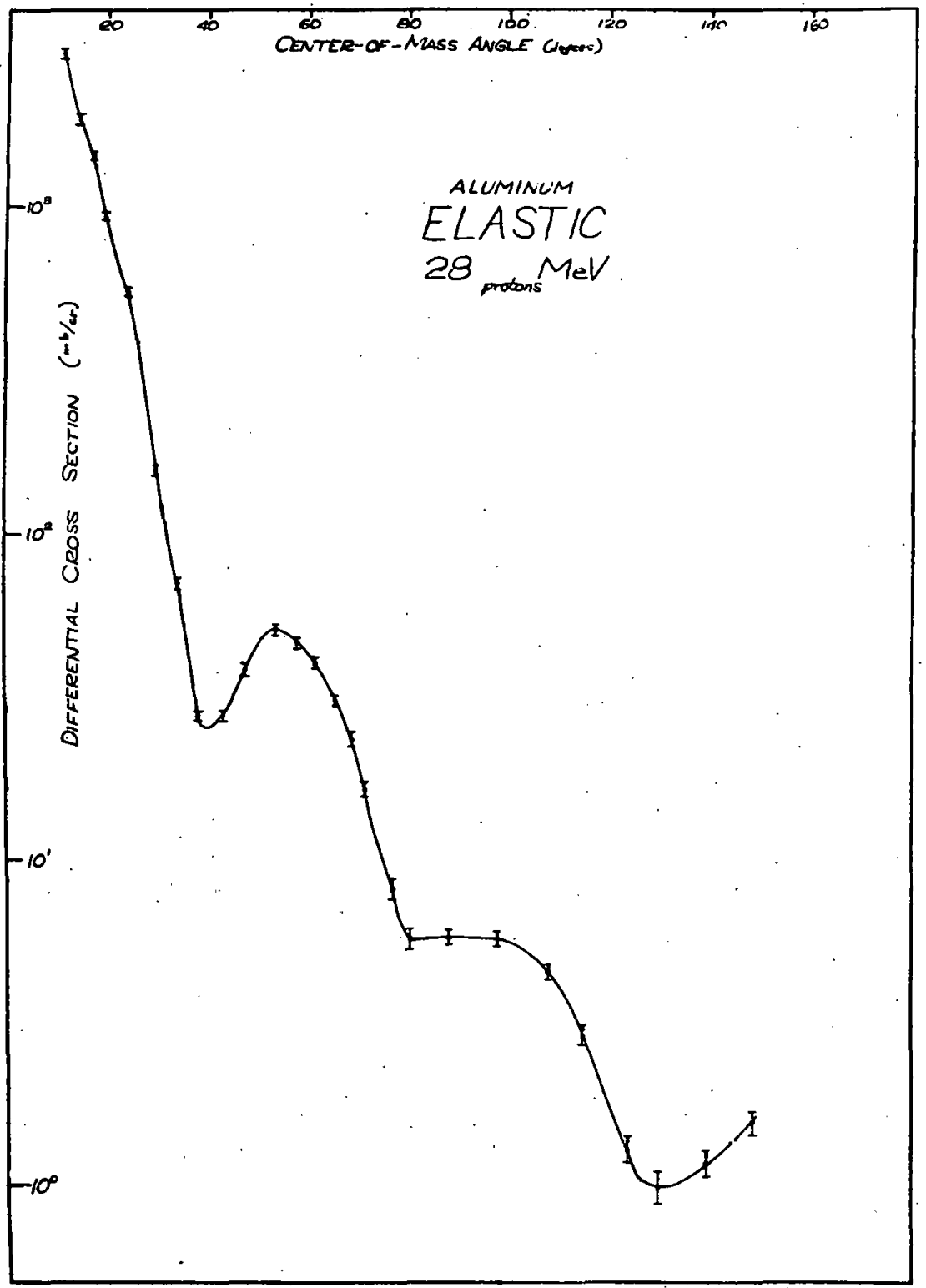

Figure 14 Elastic Scattering Differential Cross Section for Aluminum 


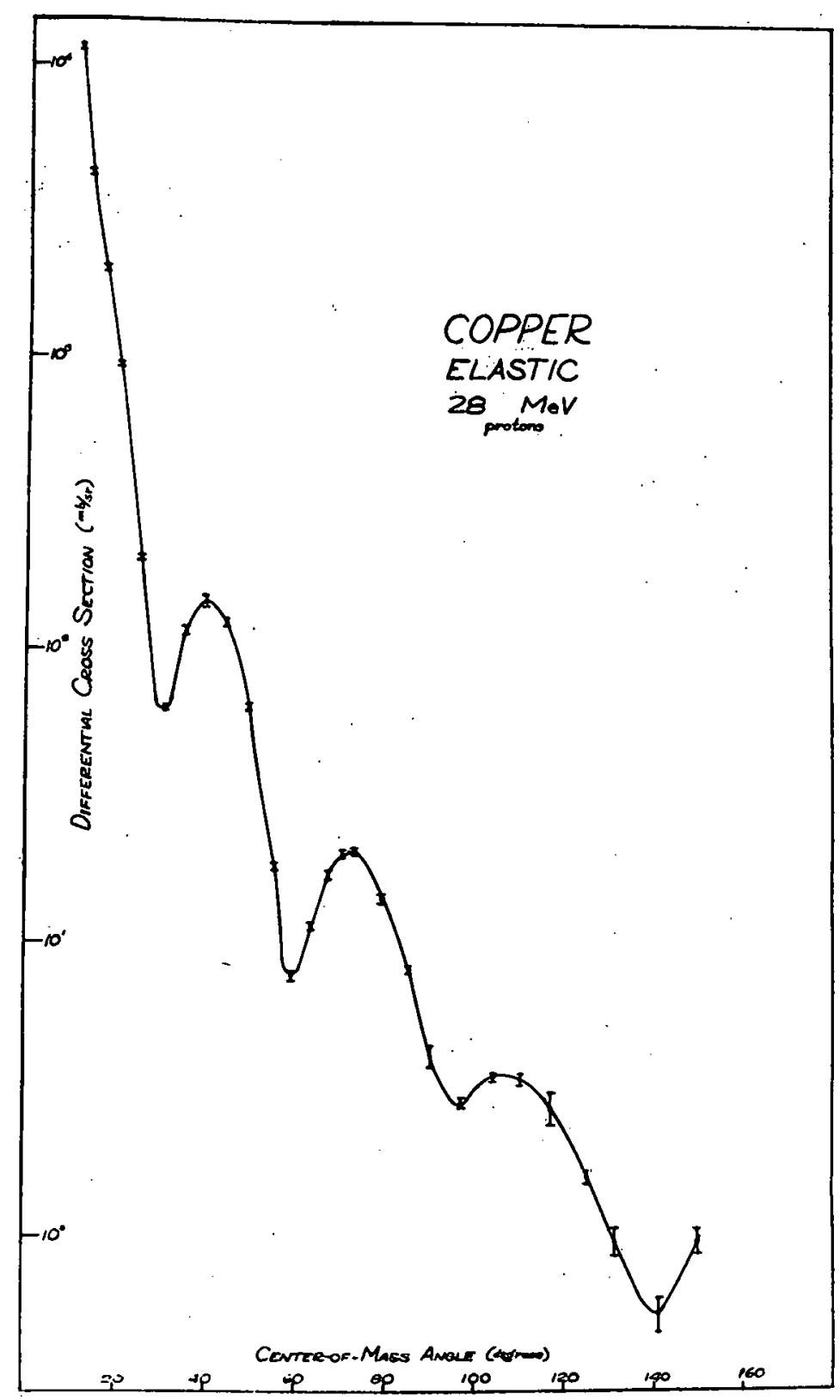

Figure 15 Elastic Scattering Differential Gross Section for Copper 


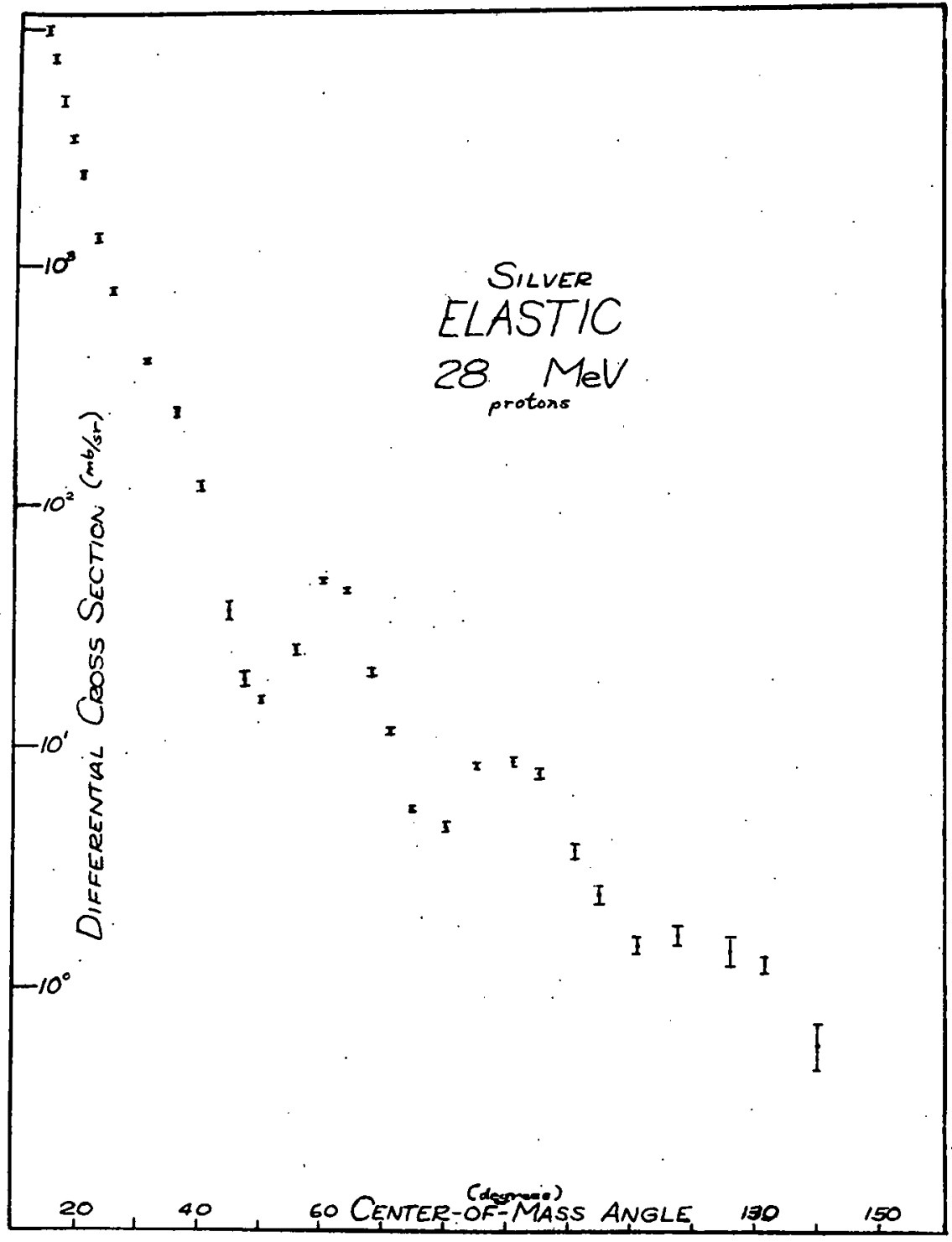

Figure 16 Elastic Scattering Differential Cross Section for Silver 


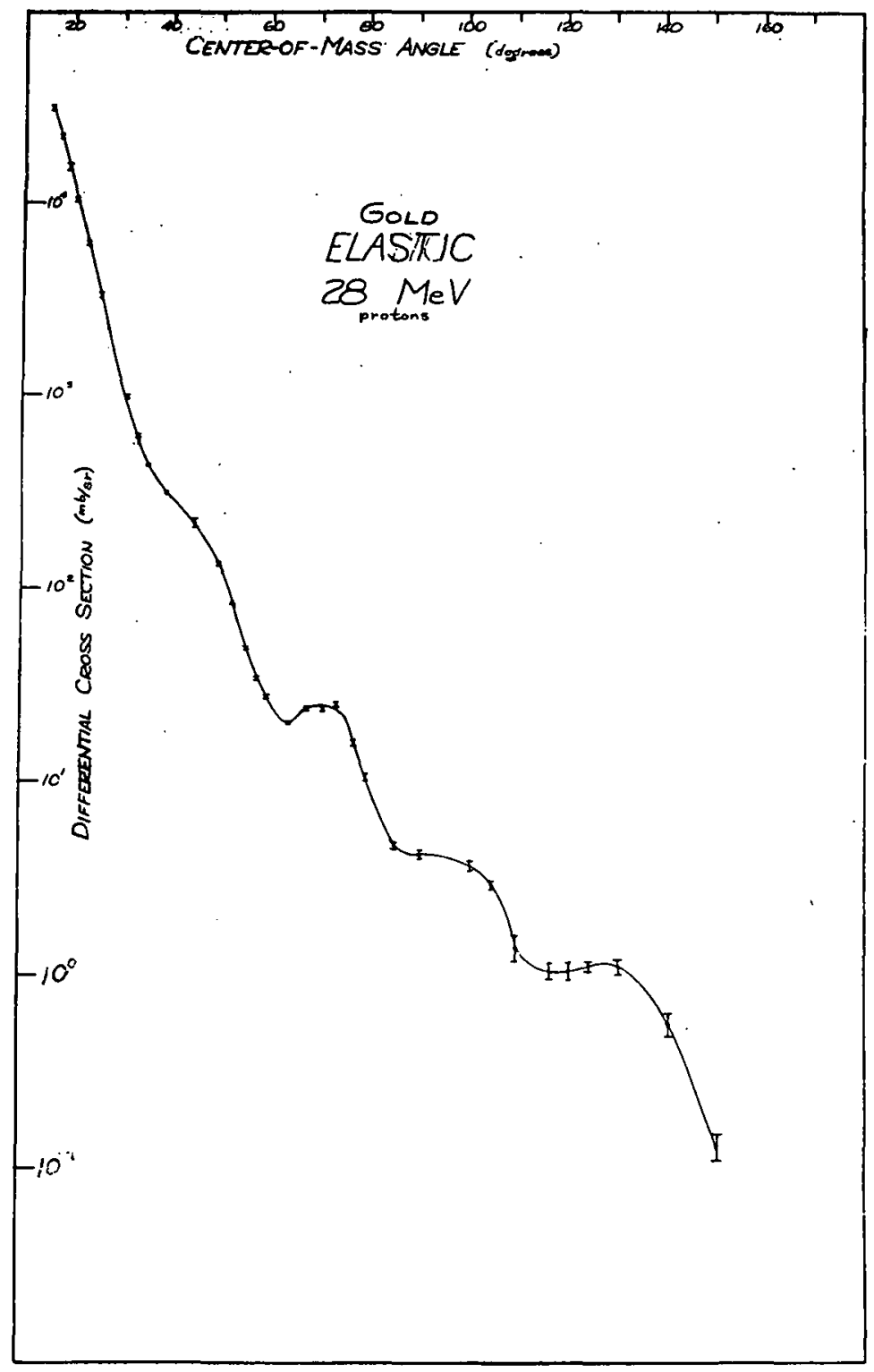

Figure 17 Elastic Scattering Differential. Cross Section for Gold 
b) Elastic and Inelastic Scattering of $30 \mathrm{MeV}$ Protons from $\underline{S 1^{28}}$ (R. K. Cole, C.N. Waddell, and associates)

The differential cross sections for the scattering of $30 \mathrm{MeV}$ protons by the ground state and the first excited state of $\mathrm{Si}^{28}$ have been measured. The elastic scattering was analyzed by means of the diffuse surface optical model of the nucleus and a very good fit to the experimental data was obtalned. In addition, the generalized (coupledchannel) model of B. Buck (1) was used to analyze the elastic and inelastic scattering angular distributions. In this model the deformed potential is characterized by a radius

$$
\mathrm{R}=\mathrm{R}_{\mathrm{o}}\left[1+\sum_{\mu} \alpha_{\mu}^{*} \mathrm{Y}_{2}^{\mu^{*}}(\theta, \varphi)\right]
$$

with a deformation parameter $\beta$ obtalned from the definition that $\beta^{2}$ is the expectation value of $\sum_{\mu}\left|\alpha_{\mu}\right|^{2}$ in the ground state. F1g. 18 compares the ratio of elastic scattering cross section to the Rutherford cross section with the results of the optical model analysis and the coupled channel analysis. Fig. 19 compares the experimental. angular distribution from the first excited state of $\mathrm{S1}^{28}$ with the results of the coupled channel calculation. A summary of the "optimum" f1t optical model parameters is presented in Table III.

The inelasific cross sections were also compared to the predictions of distorted wave calculations using ORNL code JULIE. (2) In these calculations the interaction term for the excitation of collective states is derived from a deformed optical model potential. The parameters for this 


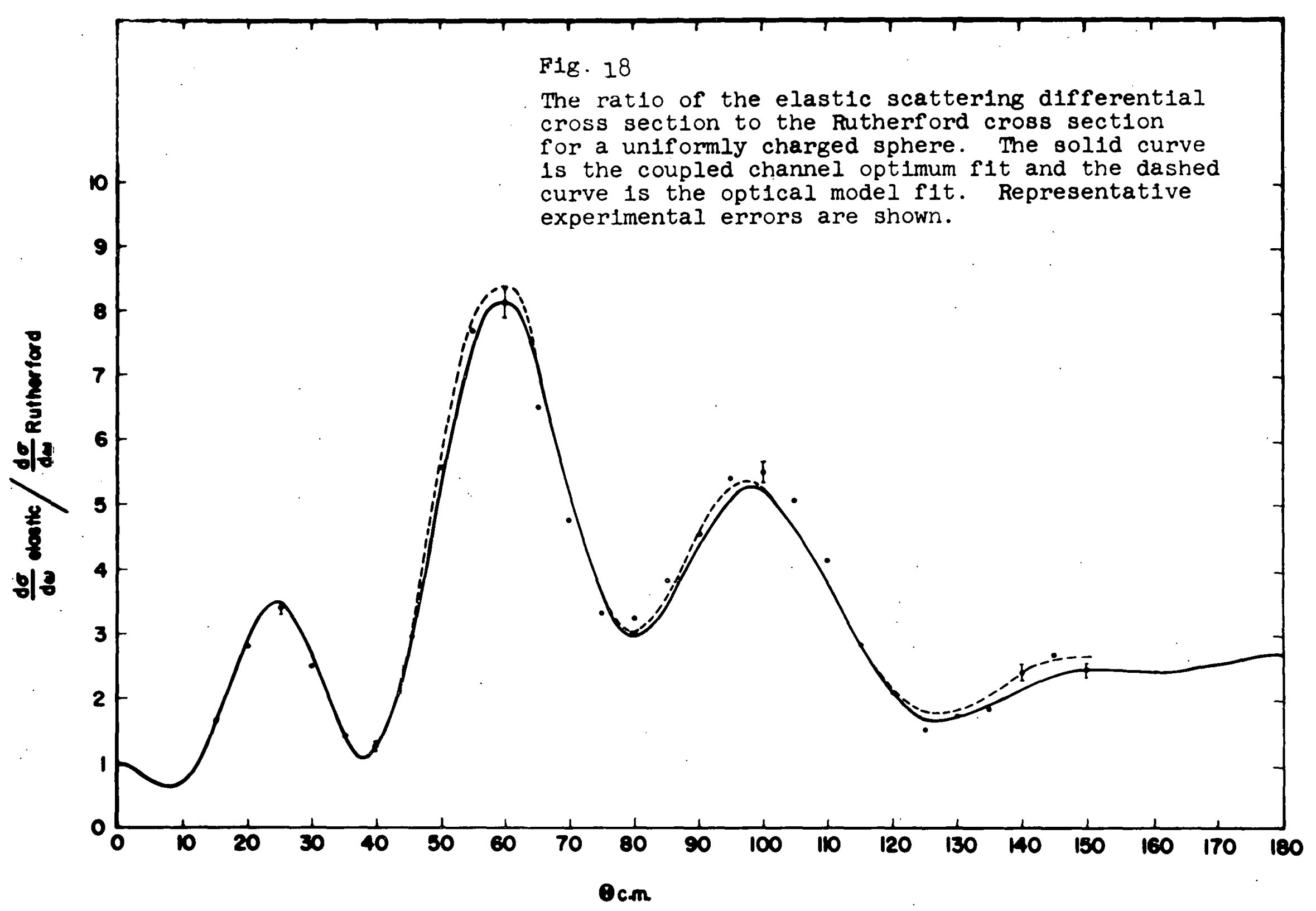




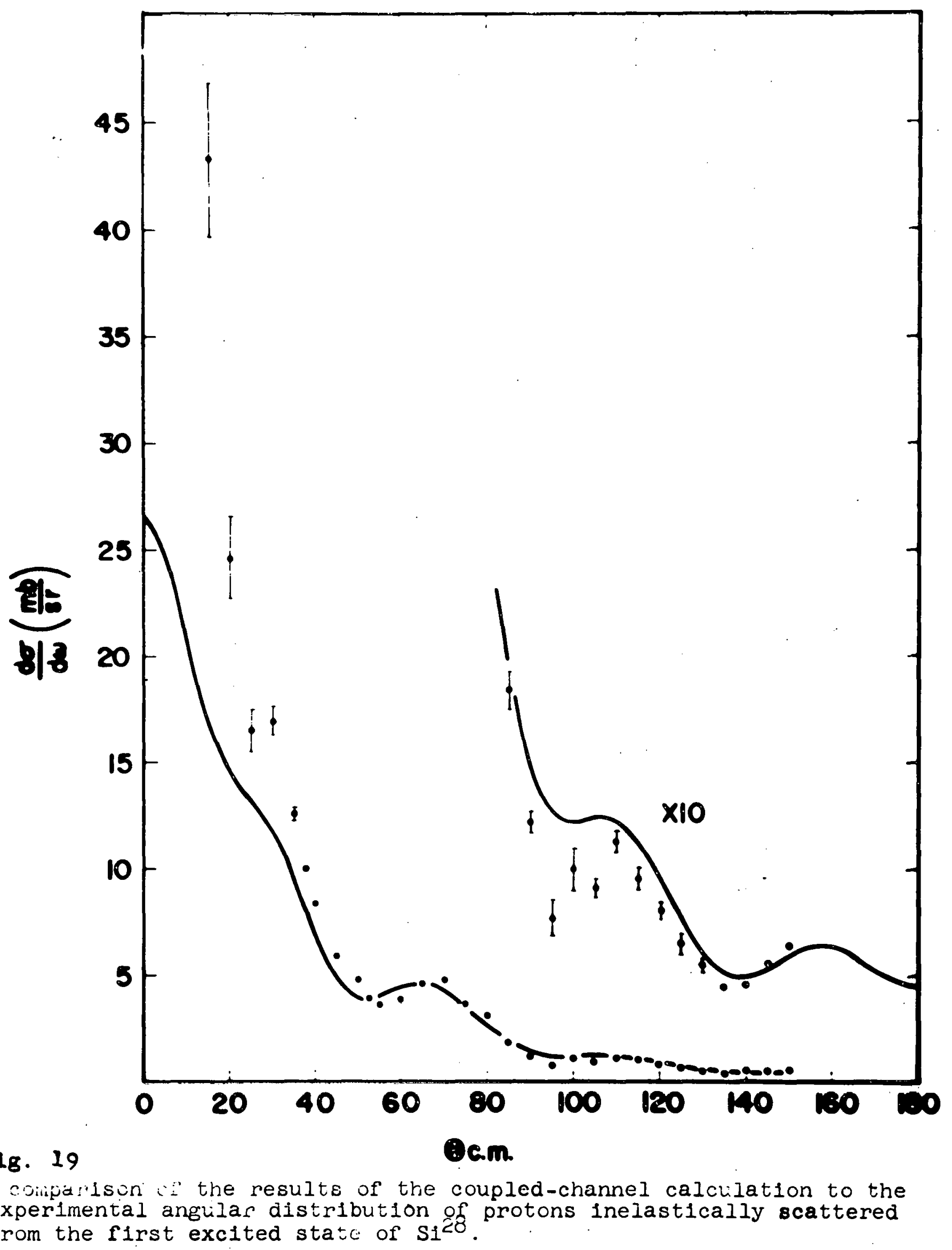


Table III

Summary of "Optimum Fit" Optical Model Parameters

$\begin{array}{ccccccccc}R_{\text {OR }} & R_{\text {OI }} & a & b & V & W_{S} & W_{V} & V_{S O} & \sigma_{R} \\ (f) & (f) & \text { (f) } & \text { (f) } & (\mathrm{MeV}) & (\mathrm{MeV}) & (\mathrm{MeV}) & (\mathrm{MeV}) & \text { (mb) }\end{array}$

\begin{tabular}{llllllllllll}
\hline optical model & 1.15 & 1.35 & 0.71 & 0.72 & 48.3 & 1.8 & 8.0 & -5.1 & 700 & --0 \\
\hline $\begin{array}{c}\text { coupled channel } \\
\text { optical model }\end{array}$ & 1.15 & 1.47 & 0.72 & 0.36 & 47.5 & 0 & 7.0 & -5.15 & 704 & 0.413
\end{tabular}


potential were obtained from the analysis of the elastic scattering data with a potential having only volume absorption. The shape of the predicted inelastic angular distribution is determined by these parameters and is independent of the deformation parameter $\beta$. However, the magnitude of the differential cross sections is proportional to $\beta^{2}$.

Two calculations were made. In the first, only the real part of the potential was deformed, and, in the second, both the real and imaginary parts of the potential were deformed using the same deformation parameter. In each case the magnitude of $\beta^{2}$ was obtained by requiring that the integrated experimental and theoretical inelastic cross sections be equal. A comparison of the experimental to the theoretical angular distributions for the first excited state of $\mathrm{Si}^{28}$ is presented in Figure 20. The predicted angular distribution for the case in which both parts of the potential were deformed (solld curve) ylelds the better fit to the experimental data.

The differential cross sections for $30 \mathrm{MeV}$ protons scattered elastically and inelastically from $\mathrm{Mg}^{24}$ have also been measured. These data will be analyzed with both the diffuse surface optical model and the "coupled channel" optlcal model of Buck.

(1) B. Buck, Phys. Rev. 130, 712 (1963).

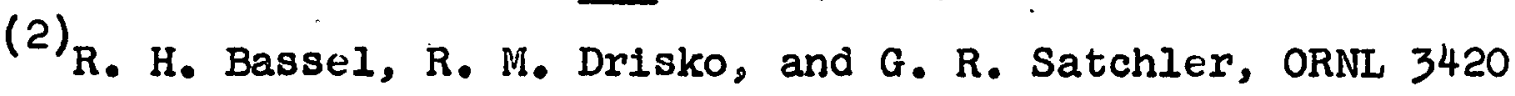
(1962), unpublished. 


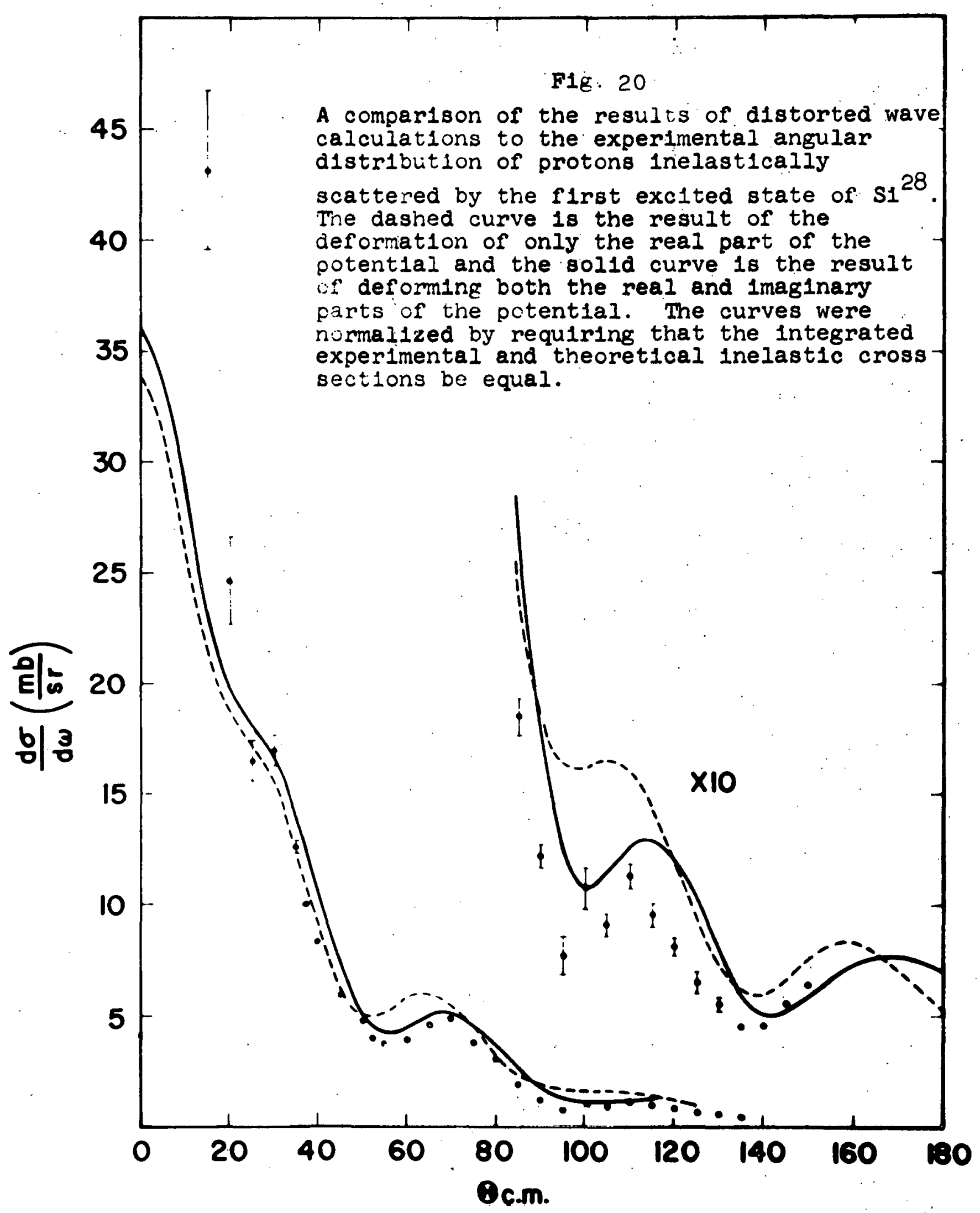


c) Inelastic Proton Spectrum of $\mathrm{He}^{3}$ (C. C. Kim and H. H. Forster)

The Inelastic proton spectrum of $\mathrm{He}^{3}$ under bombardment with $30 \mathrm{MeV}$ protons has been obtained using the same gas scattering chambers and the $\triangle E$ - E particle 1dentification system as described in the experimental setup of the $\mathrm{He}^{3}(p, d) 2 p$ reaction. Particular care was taken to avold target contamination, and background runs with hydrogen gas as the target material were taken to search for structure in the proton continuum. No such structure could be detected for the hydrogen target, while in the case of $\mathrm{He}^{3}$ a narrow peak seems to be superimposed on the $\mathrm{He}^{3}\left(p, \mathrm{p}^{\prime}\right)$ continuum. The peak occurs both above the breakup points of $\mathrm{He}^{3}+\mathrm{p} \rightarrow 2 \mathrm{p}+\mathrm{d}$ and $\mathrm{He}^{3}-3 p+n$ and has $\mathrm{a} \mathrm{Q}$ value of $\sim-10.2 \mathrm{MeV}$ and a total width at half maximum of $\Gamma \sim 1.9$ MeV. A typical spectrum obtained at $\theta_{\text {Lab }}=15^{\circ}$ is shown in fig. 21, but the peak has been seen in all spectra taken from $\theta_{\text {Lab }} \sim 10^{\circ}-40^{\circ}$. The area under the peak, calculated after continuum subtraction as indicated by the dashed curve, decreases monotomlcally within the angular range of observation; $\left(\frac{d \sigma}{d \Omega}\right)_{L a b}$ at $15^{\circ}$ is $\sim 4 \mathrm{mb} / \mathrm{sr}$. No definite explanation can be given for the peak at this point; the experiment is being continued. 


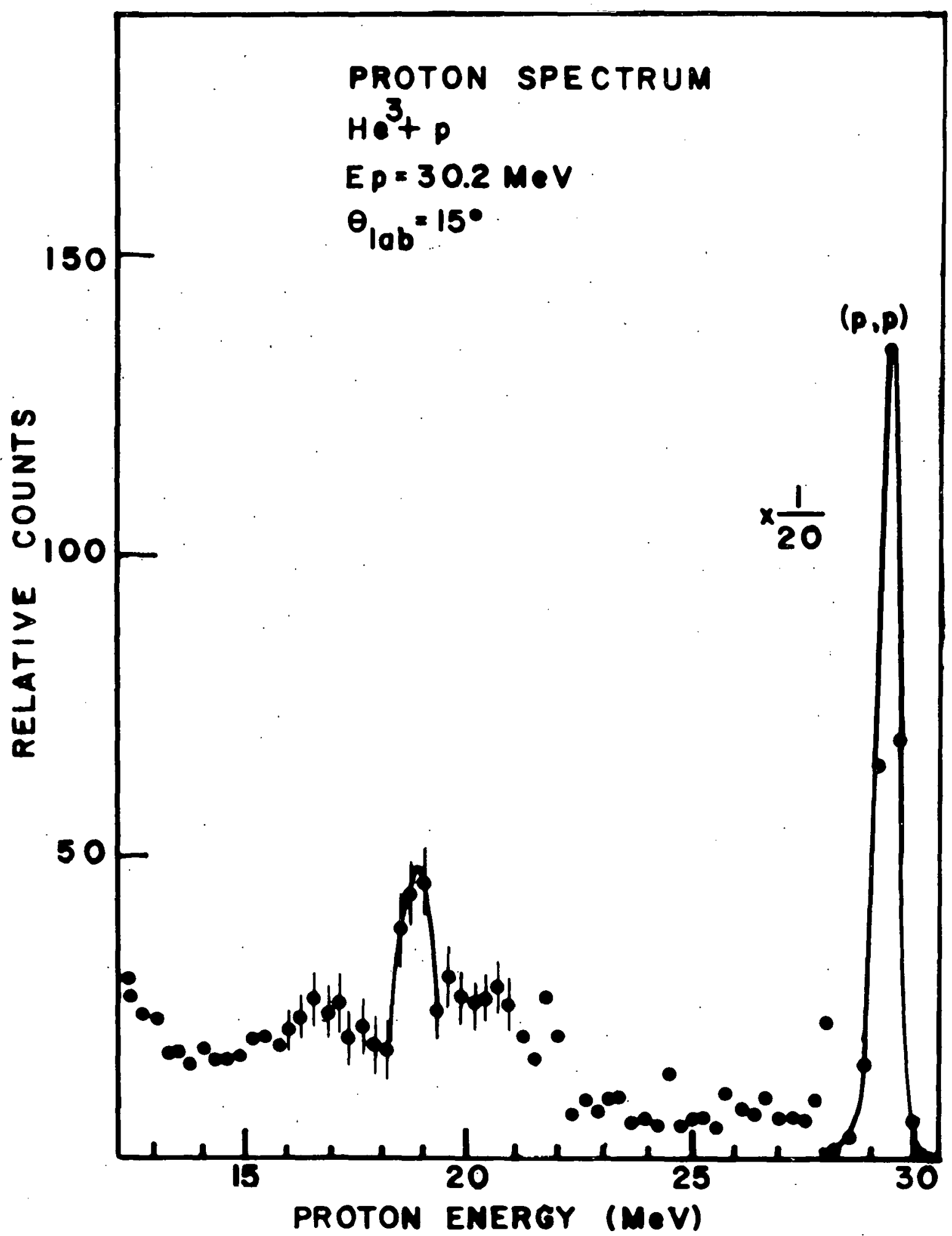

F1gure 21 
4. Proton Total Reaction Cross Sections

A program of measuring proton total reaction cross sections has been continuing for the past few years. These cross sections are obtalned from the measurement of the beam attenuation in thin targets using an "anti-coincidence" counter telescope. The experimentally determined attenuations must be corrected for the number of protons elastically scattered outside the stopping counter $\left(\theta>45^{\circ}\right)$ and for the number of:"inelast1c-particles" scattered into the stopping counter $\left(\theta<45^{\circ}\right)$ with energy sufficient to trigger a discriminator. The lack of accurate experimental data for the evaluation of these correction terms limits the number of nuclei for which measurements can be made.

a) Proton Total Reaction Cross Sections at $28 \mathrm{MeV}$ (R. K. Cole, R. M. Elsberg,* C. N. Waddell, and associates)

The reaction cross sections of a number of elements have been measured utilizing the full energy proton beam. The mean energy of the beam in the 3-MeV thick targets was $28.0 \mathrm{MeV}$. A summary of these cross sections is given in Table IV.

It has been found that the trend of $28 \mathrm{MeV}$ proton total reaction cross sections can be represented by the expression

$$
\sigma_{R}=\pi\left(r_{0} A^{1 / 3}+x\right)^{2}
$$

which is obtained from a simple semiclassical model for 
Table IV

28-MeV Proton Total Reaction Cross Sections

\begin{tabular}{lcccc} 
Element & $\begin{array}{c}\sigma_{\text {Exp; }} \\
(\mathrm{mb})\end{array}$ & $\begin{array}{c}\text { Elastic } \\
\text { Correction } \\
(\mathrm{mb})\end{array}$ & $\begin{array}{c}\text { Inelastic } \\
\text { Correction } \\
(\mathrm{mb})\end{array}$ & $\begin{array}{c}\sigma_{\mathrm{R}} \\
(\mathrm{mb})\end{array}$ \\
$\mathrm{Be} *$ & $417 \pm 8$ & $36 \pm 4$ & $24 \pm 4$ & $405 \pm 10$ \\
$\mathrm{C}$ & $453 \pm 11$ & $94 \pm 5$ & $40 \pm 3$ & $396 \pm 13$ \\
$\mathrm{Al}$ & $795 \pm 21$ & $93 \pm 10$ & $20 \pm 10$ & $722 \pm 25$ \\
$\mathrm{S1} *$ & $822 \pm 14$ & $110 \pm 10$ & $20 \pm 10 * *$ & $732 \pm 20^{*}$ \\
$\mathrm{Cr}$ & $1026 \pm 34$ & $76 \pm 20$ & $30 \pm 10$ & $980 \pm 41$ \\
$\mathrm{Fe}$ & $1022 \pm 29$ & $79 \pm 15$ & $30 \pm 10$ & $973 \pm 35$ \\
$\mathrm{Co}$ & $1120 \pm 35$ & $82 \pm 15$ & $30 \pm 10$ & $1068 \pm 40$ \\
$\mathrm{N1}$ & $1015 \pm 30$ & $91 \pm 9$ & $26 \pm 3$ & $950 \pm 32$ \\
$\mathrm{Cu}$ & $1082 \pm 34$ & $82 \pm 8$ & $24 \pm 5$ & $1024 \pm 35$ \\
$\mathrm{Zn}$ & $1109 \pm 33$ & $86 \pm 15$ & $20 \pm 10$ & $1043 \pm 36$ \\
$\mathrm{Ge}$ & $1171 \pm 63$ & $86 \pm 20$ & $20 \pm 10$ & $1105 \pm 67$ \\
$\mathrm{Ag}$ & $1370 \pm 49$ & $75 \pm 7$ & $45 \pm 10$ & $1340 \pm 52$ \\
$\mathrm{Au}$ & $2034 \pm 79$ & $130 \pm 14$ & $78 \pm 20$ & $1983 \pm 84$ \\
\hline Unpubl1shed results & & & & \\
** Prel1minary data & & & &
\end{tabular}


neutral particles of De Broglie wavelength $\lambda$ incident upon a completely absorbing nucleus of radius $R=r_{0} A^{1 / 3}$. Such a comparison is shown in Fig. 22 for $*=0.87 \mathrm{~F}$ and $\mathrm{a}$ radius parameter $r_{0}=1.21 \mathrm{~F} .(2)$

These reaction cross sections are being utilized in the optical model analysis of the elastic scattering of $28 \mathrm{MeV}$ protons described elsewhere in this report. The effect of the inclusion of the reaction cross section in the optical model analysis of $\mathrm{Cu}$ and $\mathrm{Pb}$ has been reported, (3) and a paper reporting all results is now being written.

In a survey of $10 \mathrm{MeV}$ proton total reaction cross sections it was noted that the $\sigma_{R}$ of the magic $Z$ nucleus $\mathrm{N} 1$ is smaller by about 10\% than the $\sigma_{\mathrm{R}}$ of nelghboring nuclei. (4) This shell closure effect has been studied at $28 \mathrm{MeV}$ by measuring the $\sigma_{\mathrm{R}}$ of 7 nuclel near the $\mathrm{z}=28$ shell closure. ( $\mathrm{Cr}, \mathrm{Fe}, \mathrm{Co}, \mathrm{N} 1, \mathrm{Cu}, \mathrm{Zn}, \mathrm{Ge}) .{ }^{(5)}$ These results are included in Table IV and are presented in fig. 23. Fig. 23 indicates that the anomaly near $z=28$ involves not only a decrease at $\mathrm{NI}$ but also an increase at Co. The magnitude of the measured effect is much greater than that predicted when an $\left(\frac{N-Z}{A}\right)$ symmetry term is included in the optical model potential. ${ }^{(6)}$ It was suggested that the increase at co may be due to an enhancement of proton induced reactions by the hole in the proton $f / 2$ shell. Further investigation of this effect is being made by the measurement of the $\sigma_{R}$ of $\mathrm{Fe}, \mathrm{Co}, \mathrm{N} 1, \mathrm{Cu}$, and $\mathrm{Zn}$ for $17 \mathrm{MeV}$ protons. Preliminary results of these measurements are presented in Table $V$. 


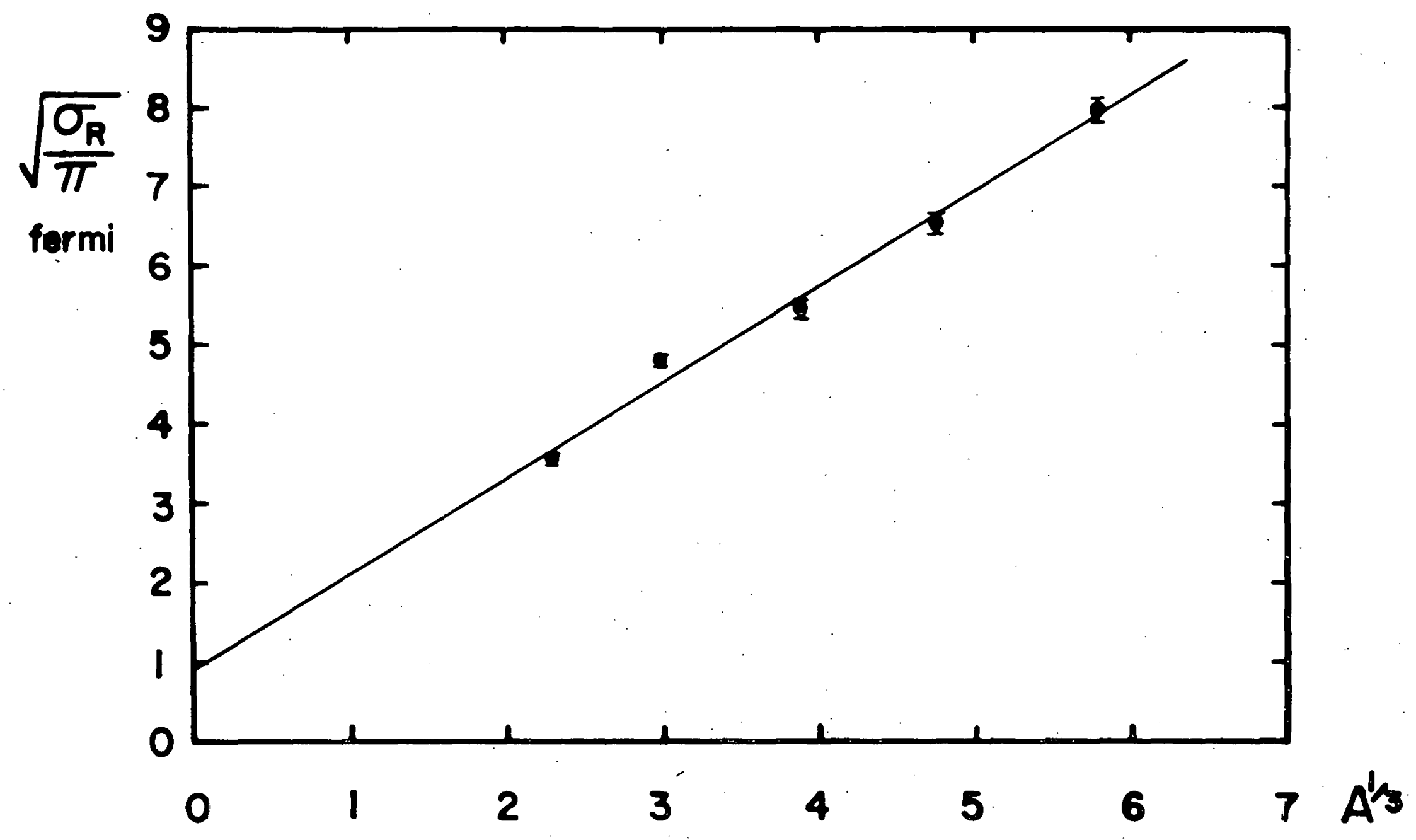

Figure 22 


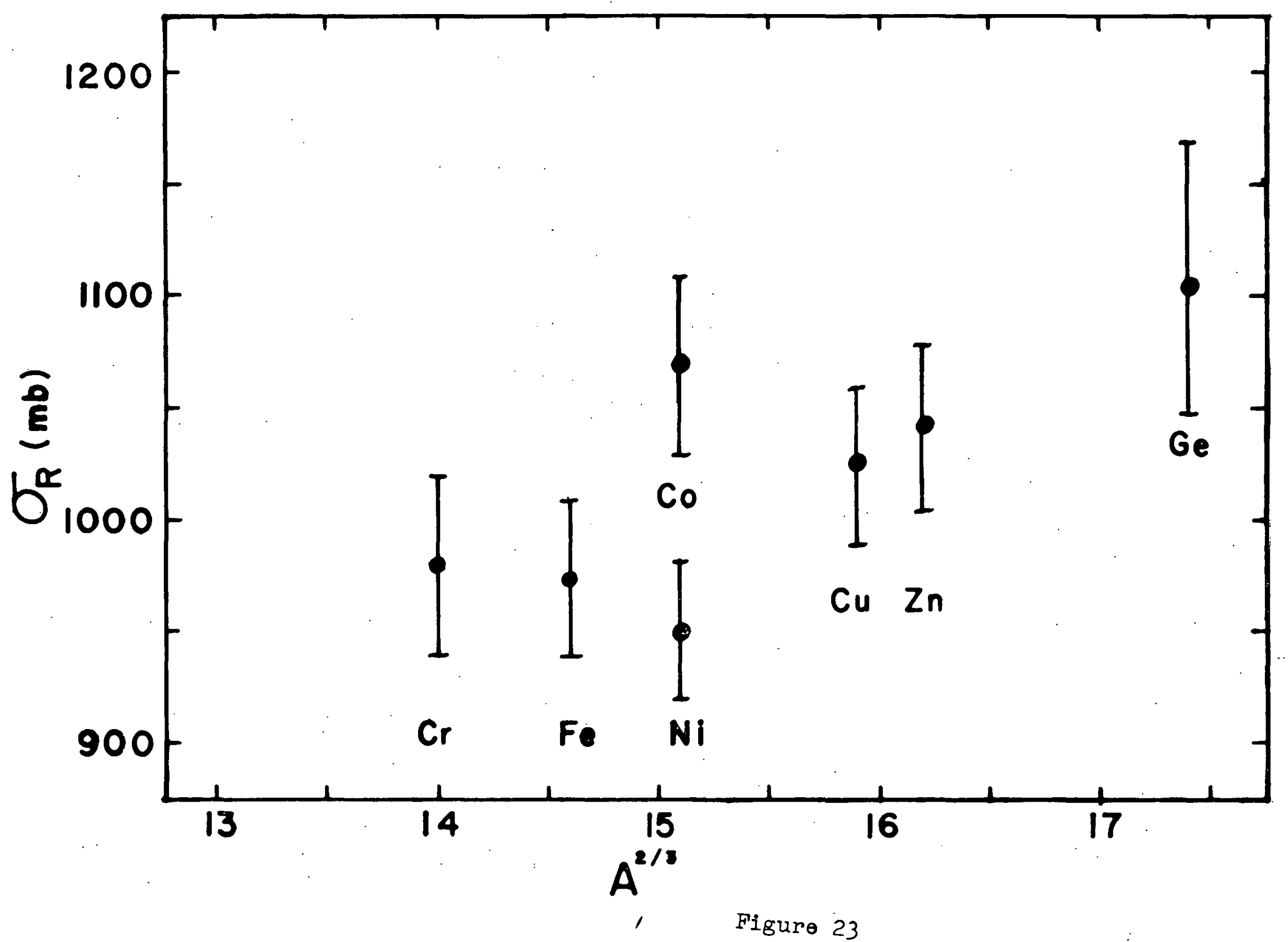




\section{Table V}

Prellminary 17-MeV Proton Total Reaction Cross Sections

Element

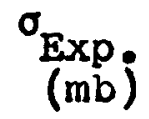

Fe

Co

N1

$\mathrm{Cu}$

$\mathrm{Zn}$

$$
1129 \pm 26
$$

$1182 \pm 34$

$1149 \pm 33$

$1215 \pm 27$

$1239 \pm 26$

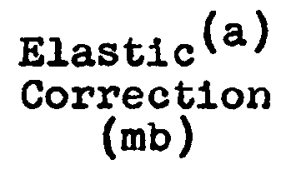

$153 \pm 12$

$136 \pm 11$

$158 \pm 13$

$146 \pm 12$

$125 \pm 10$

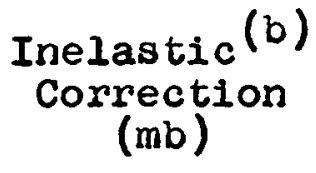

$\sigma_{\mathrm{R}}$ $(\mathrm{mb})$

\footnotetext{
(a) Dayton and Schrank, Phys. Rev.

(b) N. R. Roberson, Phys. Rev. 134, Bll7 (1964), and private communication.
} $17 \pm 3$ $993 \pm 29$

$24 \pm 8$ $1070 \pm 37$

$23 \pm 4$ $1014 \pm 36$

$22 \pm 3$ $1091 \pm 30$

$31 \pm 5$

$1145 \pm 29$ 
These preliminary results indicate the same effect noted at $28 \mathrm{MeV}$ although the magnitude of the variations is reduced. The $\sigma_{\mathrm{R}}$ of $\mathrm{NI}$ and $\mathrm{Cu}$ are somewhat larger than those obtained by Pollock(7), at $17 \mathrm{MeV}$, so we are now making additional measurements and tests of the apparatus. These measurements appear to confirm the values presented in Table V. Early publication of these results is planned.

$(1)_{M}$ Q. Makino, C. N. Waddell, and R. M. Eisberg, Nucl. Phys. 50, 145 (1964).

(2) M. Q. Makino, M.S. thesis (1964).

(3) M. A. Melkanoff, D. S. Saxon, T. Sawada, and J. S. Nodvik, "Effect of Reaction Cross Sections in Determining Optical Model Parameters," Congrès International de Physique Nucléaire, Par1s, 1964.

(4) B. D. Wilkins and G. Igo, Phys. Rev. 129, 2198 (1963).

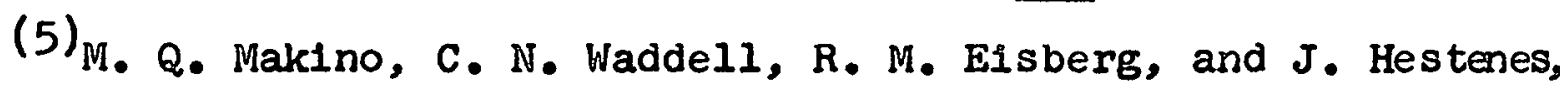
Phys. Letters 9, 178 (1964).

(6) F. G. Perey, private communication.

$(7)_{R}$. E. Pollock, Ph.D. thesis, Palmer Physical Laboratory, PUC-1962-85; PUC-1965-160, to be published. 
b) Carbon Total Reaction Cross Sections for Proton Energies between $16-28 \mathrm{MeV}$ (R. K. Cole, R. M. Eisberg, * C: N. Waddell, and associates)

The energy-dependence of the elastic and inelastic scattering of protons by $\mathrm{C}^{12}$ has been measured in this laboratory for 18 to $31 \mathrm{MeV}$ protons. (1) The optical model analysis of these data produced excellent fits at any given energy but the optical model parameters required to fit the data fluctuated excessively with energy. Tamura and Terasawa have also analyzed these data using a model in which the scattering amplitude is described by a sum of optical model and Breit-Wigner resonances. (2) Th1s analysis indicated possible broad resonances act 19.8, 20.01, and $24.9 \mathrm{MeV}\left(c_{. m}\right)$.

To investigate further the energy dependences in proton-carbon scactering, we have measured the proton total reaction cross section of carbon for proton energies from 16 to $28 \mathrm{MeV}$. (3) These results are presented in Table VI and are shown in fig. 24. In fig. 25 the band limited by the pair of dashed lines shows the experimental results With the accuracy indicated by the width of the band. The open circles show the $\sigma_{\mathrm{R}}$ predicted by the optical model analysis of Nodvik, et al. of elastic scattering data in the energy range 12 to $19 \mathrm{MeV}^{(4)}$ the closed circles show cross sections predicted by unpublished optical model analysis of elastic scattering for energies greater than $20 \mathrm{MeV}$; ${ }^{(5)}$ the triangles show the cross sections predicted by the model of Tamura and Terasawa; (2) and the square 


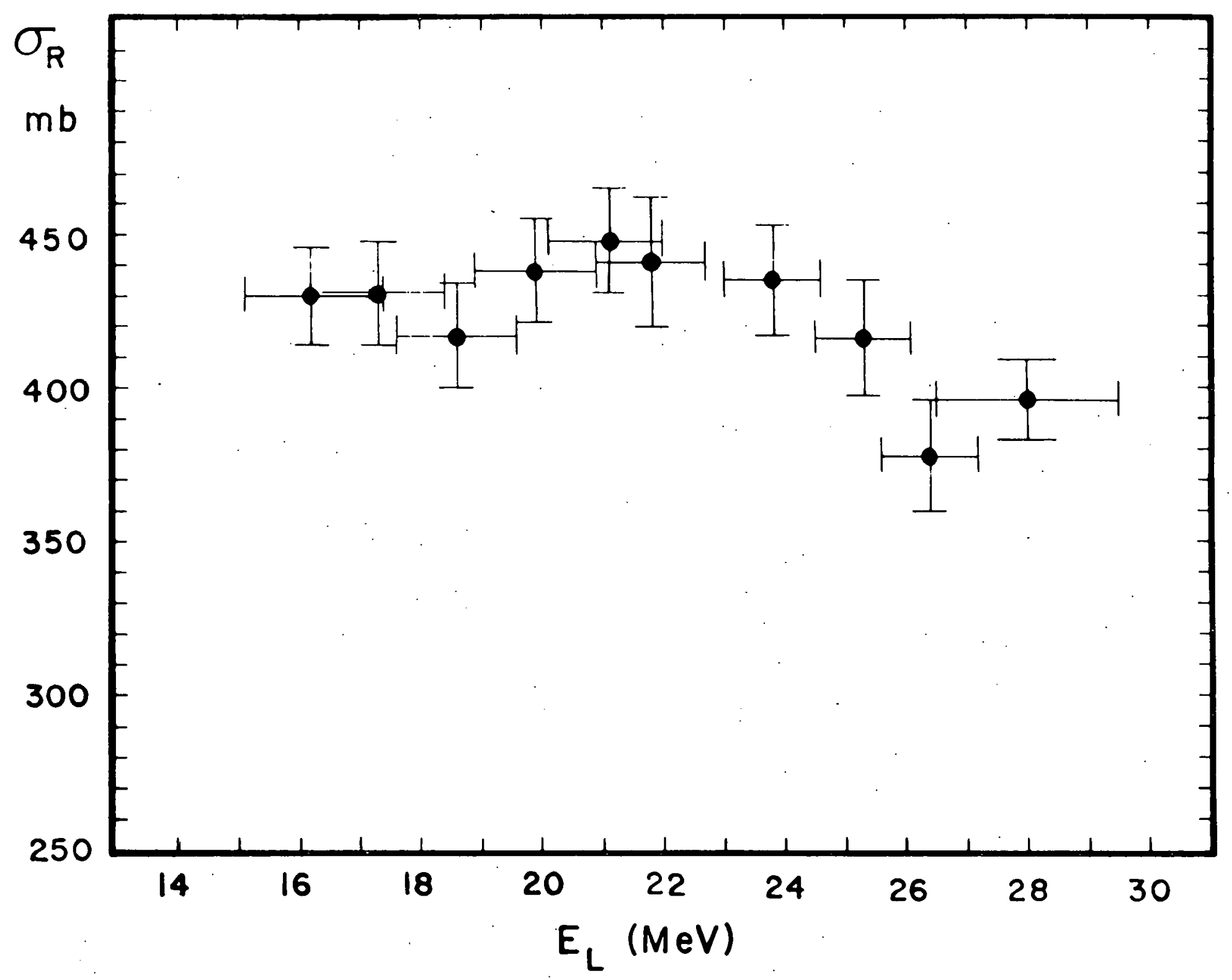

Figure 24 


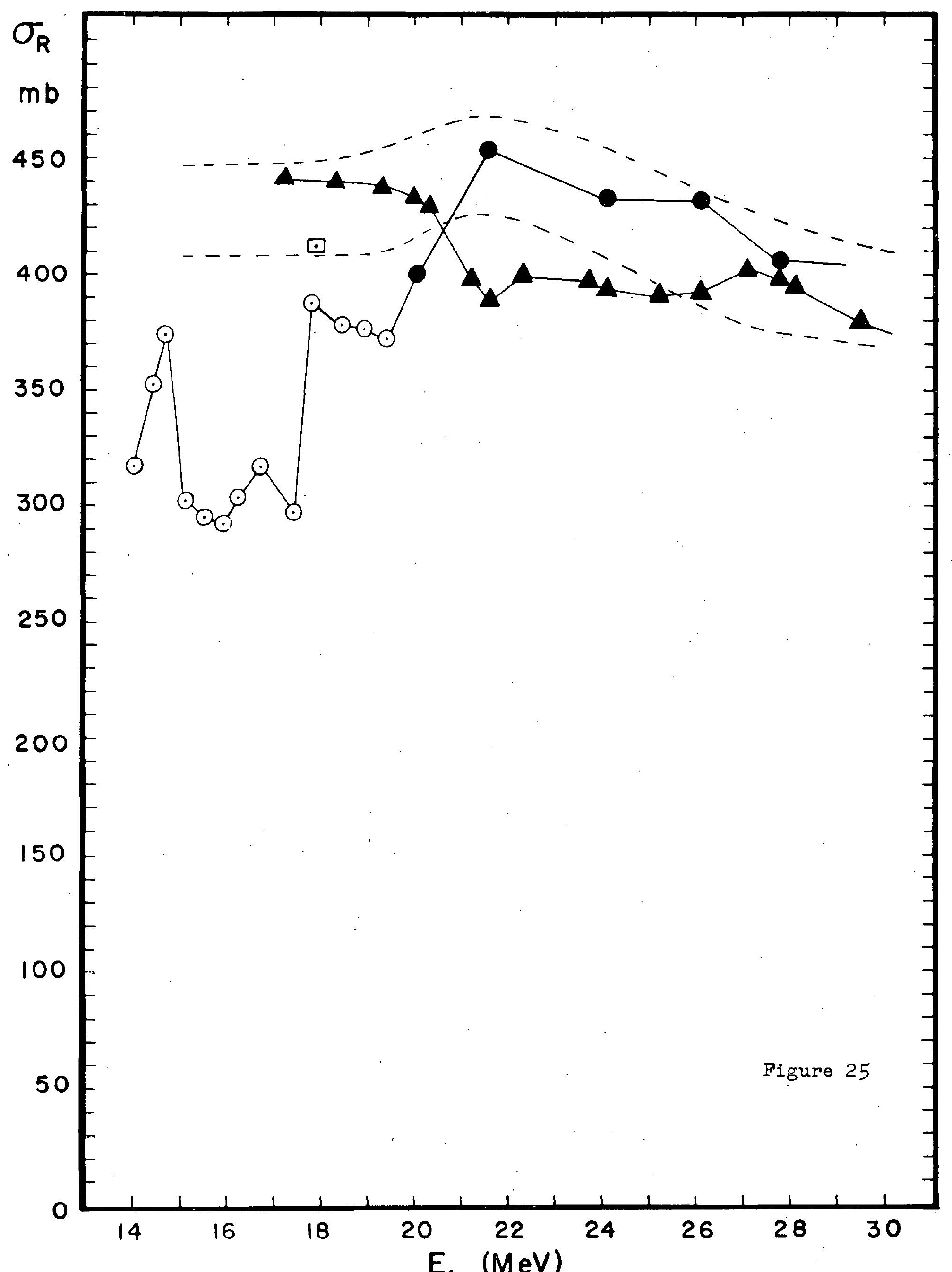


Table VI

Proton Total Reaction Cross Sections of Carbon

\begin{tabular}{ccccc}
$\begin{array}{c}\text { Energy* } \\
(\mathrm{MeV})\end{array}$ & $\begin{array}{c}\text { Experiment } \\
\text { Cross } \\
\text { Section } \\
(\mathrm{mb})\end{array}$ & $\begin{array}{c}\text { Elast1c } \\
\text { Scattering } \\
\text { Correction } \\
(\mathrm{mb})\end{array}$ & $\begin{array}{c}\text { Inelastic } \\
\text { Scattering } \\
\text { Correction } \\
(\mathrm{mb})\end{array}$ & $\begin{array}{c}\text { Total Reaction } \\
\text { Cross Section } \\
(\mathrm{mb})\end{array}$ \\
$16.2 \pm 1.1$ & $583 \pm 10$ & $221 \pm 11$ & $68 \pm 5$ & $430 \pm 16$ \\
$17.3 \pm 1.1$ & $573 \pm 13$ & $202 \pm 10$ & $60 \pm 4$ & $431 \pm 17$ \\
$18.6 \pm 1.0$ & $545 \pm 14$ & $183 \pm 9$ & $55 \pm 4$ & $417 \pm 17$ \\
$19.9 \pm 1.0$ & $548 \pm 15$ & $162 \pm 8$ & $52 \pm 4$ & $438 \pm 17$ \\
$21.1 \pm 0.9$ & $548 \pm 15$ & $148 \pm 8$ & $48 \pm 4$ & $448 \pm 17$ \\
$21.8 \pm 0.9$ & $534 \pm 19$ & $140 \pm 7$ & $47 \pm 4$ & $441 \pm 21$ \\
$23.8 \pm 0.8$ & $503 \pm 16$ & $112 \pm 6$ & $44 \pm 4$ & $435 \pm 18$ \\
$25.3 \pm 0.8$ & $476 \pm 18$ & $102 \pm 5$ & $42 \pm 3$ & $416 \pm 19$ \\
$26.4 \pm 0.8$ & $446 \pm 17$ & $99 \pm 5$ & $41 \pm 3$ & $378 \pm 18$ \\
$28.0 \pm 1.5$ & $453 \pm 11$ & $94 \pm 5$ & $40 \pm 3$ & $396 \pm 13$ \\
\hline
\end{tabular}

*The listed energies are the mean energies and the indicated energy resolution represents the energy loss in the targets. 
shows the cross section predicted by analysis of recent polarization data. (6) The agreement between theory and experiment is very good except for the analysis of the 12to 19-MeV proton elastic scattering data.

The energy dependence of the experimental reaction cross section of Be has recently been deternined. The progress of this experiment is presented elsewhere in this report.

(I) J. K. Dickens; D. A. Haner, and C. N. Waddell, Phys. Rev. 129, 743 (1963); 132, 2159 (1963).

(2) T. Tamura and T. Terasawa, Phys. Letters 8 , 41 (1964).

(3) M. Q. Makino, C. N. Waddell, and R. M. Eisberg, Nucl. Phys. (1965).

(4) J. S. Nodvik, C. B. Duke, and M. A. Melkanoff, Phys. Rev. 125, 975 (1962).

(5) J. K. Dickens, Ph.D. thesis, University of Southern Californ1a, 1962.

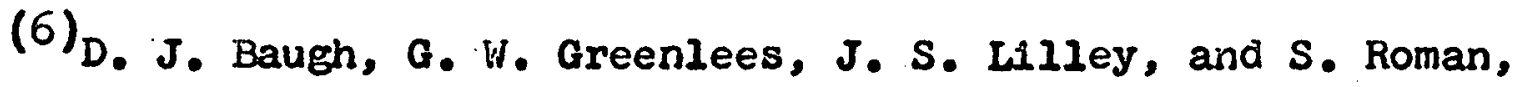
to be published. 
c) Study of Beryilium between 16 and $28 \mathrm{MeV}$ (R. K: Cole, C. N. Waddell, and associates)

The experimental total reaction cross section for beryllium in the enersy range of 16 to $28 \mathrm{MeV}$ has been completed with 2 MeV thick targets. Because of the possiblitty of a resonance structure near $E_{p}=17 \mathrm{MeV}$ this region is now being studied using thinner targets. Optical model analyses ${ }^{(1)}$ and the simple sem1classical plcture $\left[\sigma_{R}=\pi\left(r_{0} A^{1 / 3}+t\right)^{2}\right]^{(2)}$ predict that the reaction cross section for Be should be considerably less than that of carbon; however, the prellminary results Indicate that $\sigma_{R}$ for Be 18 at least as large as $\sigma_{R}$ for carbon. The neutron yield measurements on Be at $31 \mathrm{MeV}^{(3)}$ Indicate a cross section for total neutron production of $330 \mathrm{mb}$ for these reactions alone--this 18 approximately the same as the theoretical optical model prediction for the total reaction cross section. Since the angular distributions of the elastic, inelastic, and charged particle reactions are not avallable for this energy region, they w1ll also be measured. Detalled analyses using the optical model (which will include the reaction cross sections as input data) and direct interaction theorles w1ll be carried out as well as the application of these data to obtain correction terms. Because the $B e^{9}(p, d) B e^{8} \mathrm{~g} .8$. reaction has a positive $Q$-value of +0.56 $\mathrm{MeV}$, deuterons in addition to the low Q-value inelastic protons must be included in the correction terms. Analysis of the $(p, d)$ angular distributions using pickup theory 18 planned. 
$-54-$

(1) M. Melkänoff, et al., Phys. Rev, 106, 793 (1957). (2) M. Q. Makino, et az., Nucl. Phys. 50, 145 (1964). (3) T. Henderson, M.S. thesis, University of Southern Callfornia, 1963 (unpublished). 
5. Penetration of Charged Particles in Matter

a) Proton Stopping Power Measurements in Several Elements (H. Bichsel and C. Tschalaer)

The differential energy loss of fast particles is described by the Bethe formula. A basic quantity needed is the average excitation energy I of the atom. It has not been possible to obtain accurate information about I from a theory of the atom, mainly because the most important excitation energies $E_{n}$ lie in the little explored energy range between 10 and $1000 \mathrm{eV}$. Thus it is necessary to use experimental data to give quantitative energy loss data. In addition, correction terms for the binding of the electrons in the various shells have only been computed for the $\mathrm{K}$ - and the L-shell, and also have to be determined experimentally for the higher shells. At present, accurate experimental information about I is only available for aluminum, while even for copper, which is often used as a standard, I-values between 300 and $330 \mathrm{eV}$ are used in recent 11 terature. Accurate measurements are necessary to evaluate the I-value and the higher shell corrections more rellably.

Measurements were performed for several elements, and preliminary' evaluation ${ }^{(1)}$ gives the following I-values: Table VII

$\begin{array}{llllllllll}\text { Element: } & \mathrm{C} & \mathrm{Al} & \mathrm{Al}_{2} \mathrm{O}_{3} & \mathrm{~S} 1 & \mathrm{~S}^{\prime} \mathrm{O}_{2} & \mathrm{~N} 1 & \mathrm{Ge} & \mathrm{Ag} & \mathrm{Au} \\ \mathrm{Z} \text { (ave) } & 6 & 13 & 10 & 14 & 10 & 28 & 22 & 47 & 79 \\ \mathrm{I}(\mathrm{eV}) & 80 & 163 & 140 & 170 & 137 & 315 & 350 & 470 & 800 \\ \mathrm{~K}=\mathrm{I} / \mathrm{Z} & 13.3 & 12.5 & 14.0 & 12.1 & 13.7 & 11.2 & 10.9 & 10.0 & 10.1 \\ \end{array}$


Experimental method: A proton beam with an energy spread of less than $0.4 \%$ and a well-known average energy $E_{0}$ penetrates through an absorber foll of the material under investigation (f1g. 26). The energy distribution of the emergent beam is determined in a semiconductor detector, and the average emergent energy $E_{1}$ can be computed. The same foil is used for many measurements with different values of $E_{0}$, to give many sets of energy loss data. The incldent beam energy $E_{0}$ is obtained from a magnetic particle analyzing magnet, where the geometry of the beam path is determined by a system of five slits (as narrow as $0.2 \mathrm{~mm}$ ) located in the homogenous part of the magnetic fleld. The radius of curvature (about $1 \mathrm{~m})$ through the five slits can be determined to an accuracy of about $0.1 \mathrm{~mm}$. The magnetic field is measured with $a$ proton magnet1c resonance probe, and has been mapped the same way. Thus it is possible to determine the incident beam energy to an accuracy of about $0.1 \%$. The absorber folls are flat, circular disks of $1 "$ diameter, with thicknesses of the order of: $0.1 "$. Their thickness is measured in many different places to an accuracy of $0.00001 "$, and the1r surface density also is determined. The estimated accuracy is better than $0.1 \%$. The homogenelty w1ll be measured with the proton beam, but, to date, only the center of each foll has been used for stopping power measurements.

The measurement of the average emerging energy $E_{1}$ has caused the most serious problem to date. Commercial ilthiumdrift silicon detectors with a nominal sensitive depth of $2 \mathrm{~mm}$ are used for the determination of the energy of individual 


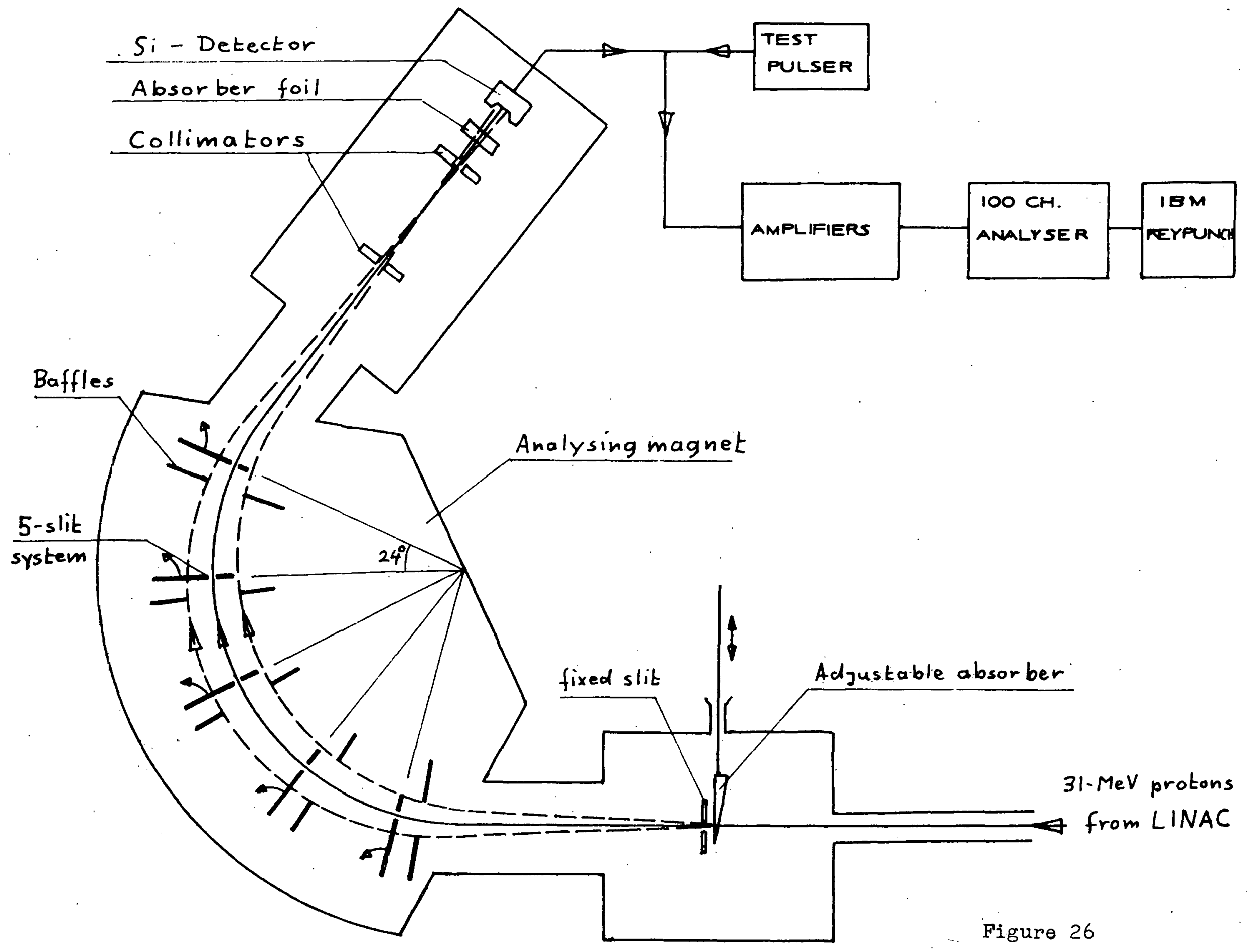


protons. The energy spread amounts to about 0.5 to $1 \mathrm{MeV}$ (full width at half maximum), and can reasonably be explained by the known data about straggling. Further investigations w1ll be necessary to explain the detalled shape of the distribution function. With sufficient numbers of particles it should be possible to determine the average energy of the distribution to an accuracy of about $1 \%$ of the spread. Measurements to date have shown random fluctuations of about $10 \%$ of the spread, and we belleve that this has been caused by excessive counting rates. Th1s problem is now under investigation, but has not been solved as yet. The energy response of the detectors has been studied, and it 18 found that the accuracy of the absolute energy determination is better than $10 \mathrm{keV}$ ( $\mathrm{flg}$. 27). The over-all accuracy of our data thus is almost entirely influenced by the measurement of the average final energy $E_{1}$. An idea of the present state of the art can be obtained from 118.28 .

The determination of I-values will depend also on systematic, undetected errors, and a major effort will be made to track down possible sources of such errors. Some small contributions are to be expected from the performance of the magnet (differential hysteresis effects, etc.). If single crystals are used for absorbers, directional effects w11l have to be studied. Tabulated values of the density of some materials are not rellable. To date, our data have not been accurate enough to get any detalled information about the shell correction funotions. We have used data from other sources to make preliminary corrections, and 1 is to be 


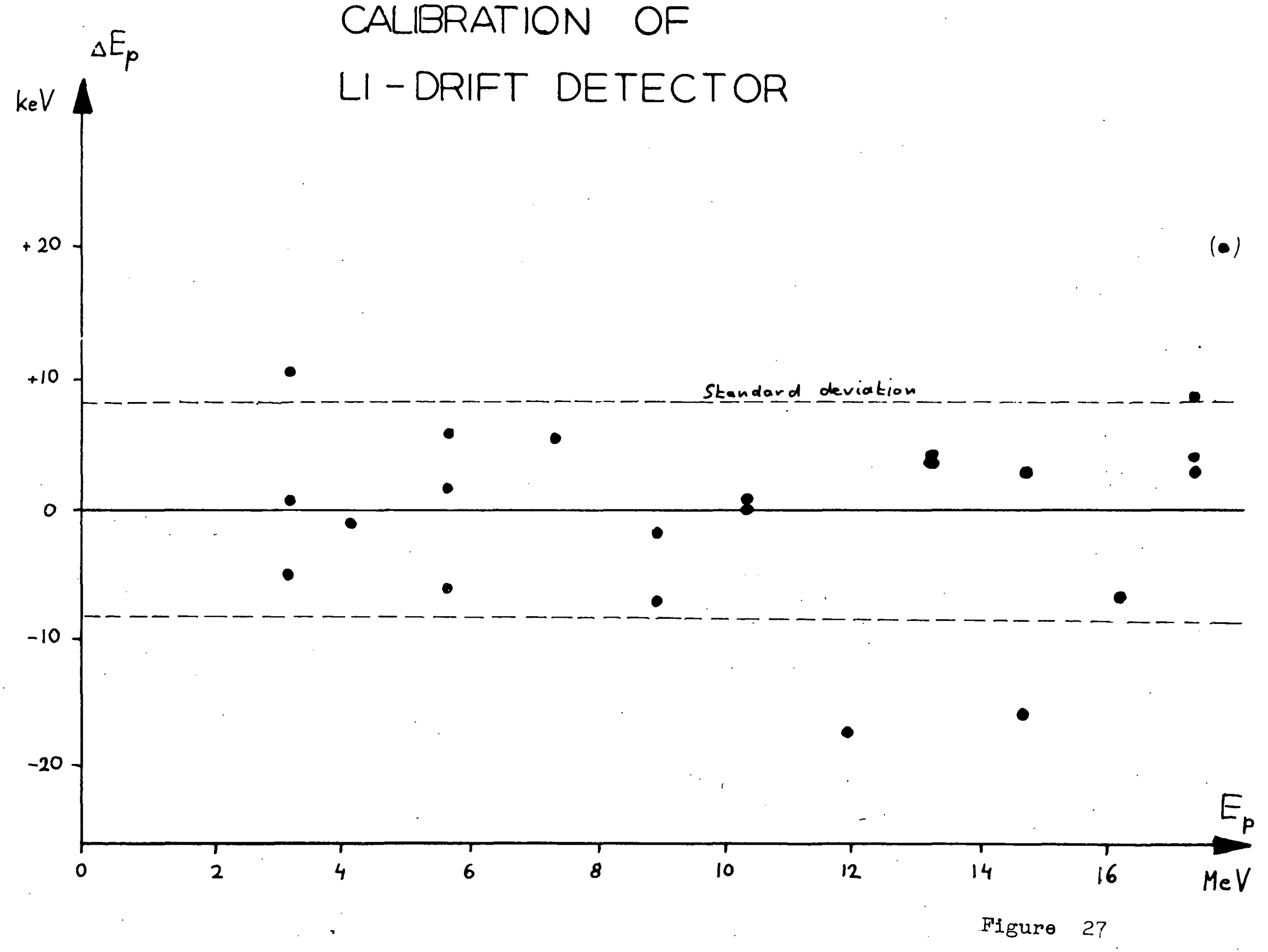


Best fit of theoretical absorber thicknesses

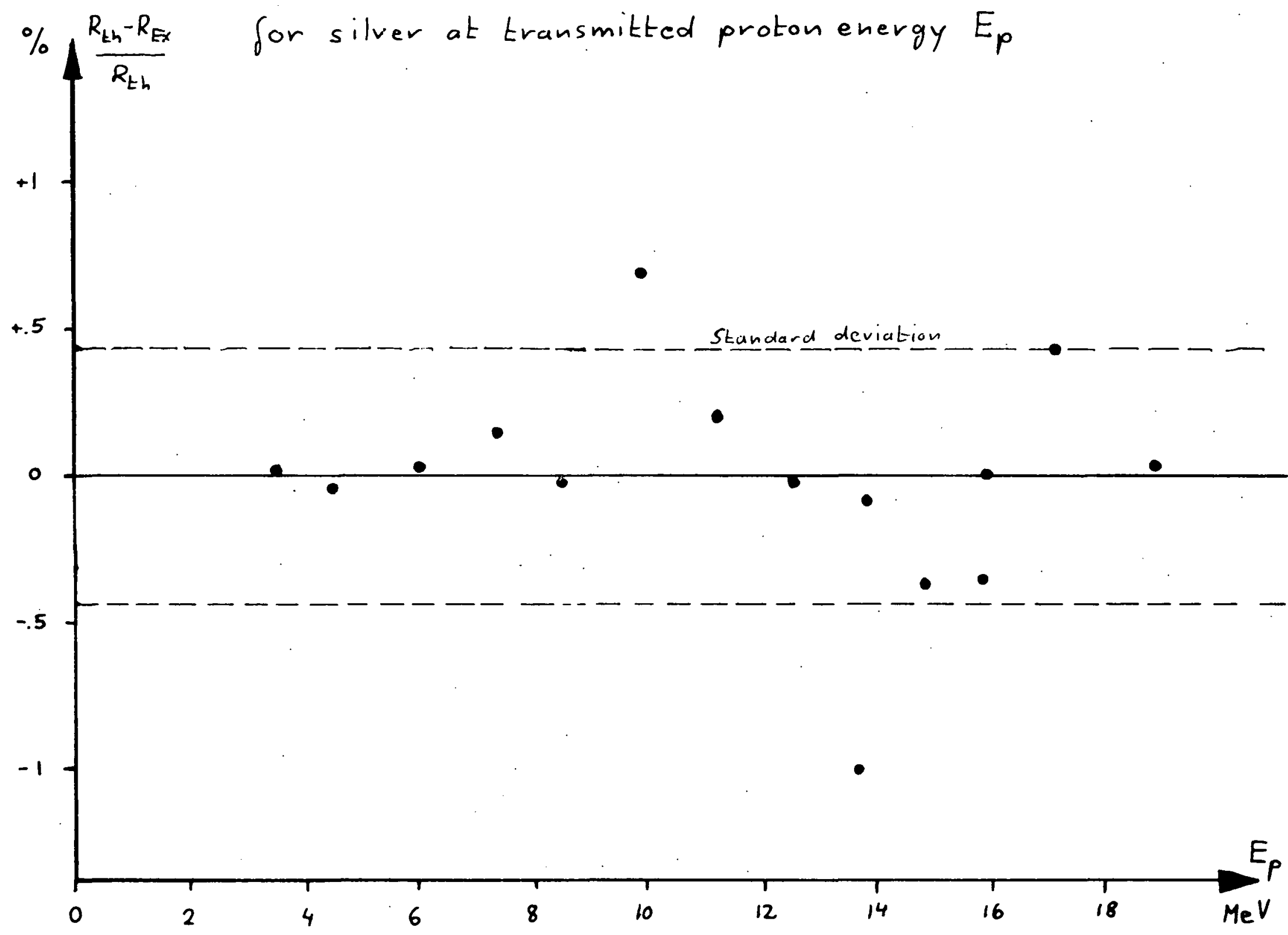

Figure 28 
expected that the I-values will change somewhat as more information about the shell corrections becomes avallable. Thus 1t w1ll be necessary to use the I-values of Table VII with caution. The errors quoted take into account only the random errors of the experimental data, but not any suspected. systematic efrects.

b) Calculations of Shell Corrections (Hans Bichsel)

Walske's calculations of L-shell corrections have been repeated and extended to give more precise and extensive values. The data are avallable on IBM cards, and eventual publication is planned.

(I) H. Bichsel and C. Tschalaer, Bull. Am. Phys. Soc. II, 10, 723 (1965). 


\section{THEORETICAL PROGRAM}

1. Nucleon-Nucleon Scattering from One-Boson Exchange Potentials (Bruce L. Scott and Ronald A. Bryan, Lawrence Radiation Laboratory, Livermore, Calif.)

The work involving an attempt to understand the nucleon-nucleon interaction in terms of single exchanges of Bosons has been completed. The preliminary study $(1)$ involving a static model with a zero cutoff and excluding $S$-waves was reasonably successful so that attempts to improve the model were begun. The improvements were: a) keeping all terms in the scattering amplitude up to quadratic in the particle momenta, b) introducing a momentum space cutoff so as to be able to include $\mathrm{S}$-waves in the calculation. In this calculation s1x Bosons were introduced including the well-known $\pi, \rho$, $\omega$, and $\eta$ as well as two, as yet undiscovered, scalar mesons, $\sigma_{0}$ and $\sigma_{1}$. Parameters in the theory are the coupling constants for the $81 x$ mesons, the magnetic coupling constant for the $\rho$, the cutoff parameter and the masses of the two scalar mesons. A best fit to the phase parameters of Arndt and Mac Gregor was found by adjusting these parameters. The results $^{(2)}$ of this search were presented at the A.P.S. Meeting in Hawall and are now being prepared for publication.

(1) Ronald A. Bryan and Bruce L. Scott, "Nucleon-Nucleon Scattering from One-Boson-Exchange Potentials," Phys. Rev. 135, B434 (1964).

(2) Bruce L. Scott and Ronald A. Bryan, Bull. Am. Phys. Soc. 10, 736 (1965). 
2. Effect of Antisymmetrization on Stripping Reactions using Distorted Waves (B. L. Scott and George C. Strobel)

The effect $(1,2)$ of including the coherent knockout contribution to the scattering amplitude in a distorted wave Born approximation calculation of a deuteron stripping reaction was considered in detall. It was found that, due to the rapld falloff of the overlap integrals outside the nuclear region, coupled with the large cancellations of the integral inside the nucleus (due to the rapldiy oscillating distorted waves), the knockout contribution was very small. This is in contradiction to earlier crude calculations which had Indicated that the knockout amplitude could be very important. In this work, the nucleus was assumed to be described by a $j-j$ coupled shell model. Any correlations in the nuclear wave function will weaken the above results.

(1) George L. Strobel, "Effects of Antisymmetrization on Stripping Reactions using Distorted Waves," Ph.D. Dissertation, Unlversity of Southern California, June 1965, issued as Nuclear Physics Laboratory Technical Report No. 12, January 1965.

(2) George L. Strobel and Bruce L. Scott, "Coherent Knockout Amplitudes in Deuteron Stripping Reactions," Phys. Rev. (in press). 
3. Analytic Expressions for the Born Approximation to Certain Elements of the Reactance Matrix in $e^{-}-$H Scattering (B. L.

Current interest in inelastic electron-hydrogen scattering led to a reconsideration of calculations of the various cross sections. Certain integrals which appear when using the Born approximation in the reactance matrix approach, which had heretofore been numerically integrated, were found to be expressible $(1)$ in terms of Legendre functions of the second kind and their derfivatives, leading to analytic expressions for the reactance matrix elements. This procedure is very useful for purposes of computing.

(1) Bruce L. Scott, Phys. Rev. 137, A717 (1965). 
4. Classical and Quantum Theory of Spin (J.S. Nodvik)

The most important aspect of the classical relativistic equations of motion for a spinning particle is the appearance of non-holonomic constraints ${ }^{(1)}$ which are encountered in defining a set of Fermi axes relative to which the intrinsic rotation of the particle is to be measured. In spite of the appearance of these constralnts it has been found possible to cast the equations of motion into Hamiltonian form and to quantize them according to the standard procedure of replacing Poisson brackets by commutator brackets divided by $1 \mathrm{~h}$. Although the result is a self-consistent quantum theory describing a particle which possesses an intrinsic spin, this theory is fundamentally different from the theory which has the Dirac equation as its basis. This difference can be traced to the assumption that the particle possesses a rest system, i.e. that its motion is such that it is always possible to find an inertial system in which the particle is instantaneously at rest. Any departure from this assumption is necessarily a drastic one whlch presents formidable difficulties. Nevertheless it has been found possible to abandon this assumption and to show that the Dirac equation follows directly (though not simply) from the single assumption that the electron is a point charge which always moves with the speed of light. The following have been investigated in great deta1l: the mathematical description of the kinematics, consistent with the special theory of relat1vity; the Lagrangian and classical equations of motion; the Hamiltonian 
form of the equations of motion; the quantization of the equations, resulting in the Dirac equation. A three-part paper is now being prepared for publication. 
APPENDIX 
Faculty

Hans Bichsel, Associate Professor

Robert K. Cole, Assistant Professor

Delbert W. Devins, Visiting Assistant Professor

Left project september 1965

Harriet H. Forster, Professor

John S. Nodvik, Associate Professor

Maurice H. I. Pryce, Distinguished Professor, Chlef Investigator Joined project May 1965

R. Rajaraman, Assistant Professor Joined project September 1965

Harbhajan S. Sandhu, Visiting Assistant Professor

Bruce L. Scott, Assistant Professor Left project September 1965

Charles N. Waddell, Associate Professor

Gerhard L. Weissler, Professor, Chief Investigator

Left project 1965

Rezearch staff

Stanley M. Bunch

Roger R. Dittman

Chong C. Kim

Jacques R. Raynal

S. Michael Scarrott

George I. Strobel
Left project August 1965

Ieft project August 1965

Joined project February 1965

Left project July 1965

Joined project September 1965

Left project August 1965 
Predoctoral Research Assistants

Gregor Baladjanian

Erik J. Bochove

Joachim Büchner

Ieft project September 1965

Chia-cheh Chang

Ronald J. Crowley

Ieft project September 1965

Jür1 Eenmaa

Joined project March 1965

Hagop M. Hokhikian

Kent A. Huber

Richard V. Johnson

Joined project June 1965

Left project September 1965

Paul S. Lewis, Jr.

Motoji Q. Makino

Darilel G. Murrtägue

Ted W. Rybka

Joined project June 1965

Left project September 1965

Chrịt,oph Tschalär

Lester C. Welch 
Full-time Technical Staff

Technicians

Richard E. Alvidrez, Junior Accelerator Operator

Thomas J. Fraker, Principal Accelerator Operator

Charles J. Himelhoch, Junior Accelerator Operator

Ieft project July 1965

Richard J. Huard, Senior Accelerator Operator Joined project April 1965

Thomas K. Inman, Chief Accelerator Technician

Julio C. Quiroga, Principal Accelerator Operator

Earl I. White, Chief Accelerator Engineer

Left project September 1965

Electronic Technicians

Ben-ami Katz, RF Techniclan and Electronics Designer Joined project June 1965

Hanno H. Knorr, Principal Electronics Technician Left project July 1965

Joe B. Yee, Principal Electronics Designer

Machine Shop

John U. Carnes, Experimental Machinist

Left project March 1965

Eckhard Heyden, Experimental Machinist

Left project August 1965

John Iepis, Experimental Machinist

David T. Pohl1, Experimental Machinist

George V. Rodriguez, Experimental Machinist

Joined project April 1965

Bmoe B. Varnes, Experimental Machinist and Welder 


\section{U.S.C. LINAC PUBLICATIONS}

\section{Conference Contributions}

"Proton Total Reaction Cross Section of $\mathrm{c}^{12}$ from 16- to 28-MeV." M. Q. Makino, C. N. Waddell, and R. M. Elsberg, Bull. Am. Phys. Soc. 9,705 (1964).

"The Elastic Scattering of $28 \mathrm{MeV}$ Protons."

R. K. Cole, R. Dittman, H. S. Sandhu, and C. N. Waddell, Bull. Am. Phys. Soc. 9, 724 (1964).

"A Simple Analysis of the $\mathrm{Ii}^{6}(\mathrm{p}, \mathrm{pd}) \mathrm{He} \mathrm{H}^{4}$ Reaction."

D. W. Devins, H. H. Forster, and B. L. Scott, Rev. Mod. Phys. 37, 396 (1965).

"The $D(p, 2 p) n$ Reaction at 31 MeV."

S. M. Bunch, C. C. Kim, and H. H. Forster, Rev. Mod. Phys. 37, $523(1965)$.

"Angular Correlation of Coincident Charged Particles Emitted in the $\mathrm{p}+\mathrm{He}^{3}$ Reaction."

H. H. Forster, C. C. Kim, D. W. Devins, and S. M. Bunch, Bull. Am. Phys. Soc. 10, 423 (1965).

"Range-Difference Measurements for Protons in C, Al, Sapphire, Si, Quartz, Ge, and Ag."

Hans Bichsel and Christoph Tschalär, Bull. Am. Phys. Soc. 10, 723 (1965).

"Nucleon-Nucleon Scattering and One-Boson-Exchange Potent1als." Bruce L. Scott and Ronald A. Bryan, Bull. Am. Phys. Soc. 10, 736 (1965).

"Wire Orbit Measurements with a Pulley of Low Friction." Hans Bichsel, International Symposium on Magnet Technology, Stanford University, September 1965.

Technical Reports

"Proton Total Reaction Cross Sections of Carbon from 16 to 28 MeV.

Motoji Q. Makino, Charles N. Wadde1I, and Robert M. Eisberg, December 1964.

"Effect of Antisymmetrization on Stripping Reactions Using Distorted Waves."

George I. Strobel, January 1965.

"Coherent Knock out Amplitudes in Deuteron Stripping Reactions." George L. Strobel and Bruce L. Scott, March 1965.

"Computer Calculation of Angular Momentum Coupling Coefficients and of $(d, p)$ Stripping Reaction Cross Section."

George I. Strobel, Febmuary 1965. 
Theses

"The $D(p, 2 p) n$ Reaction at 31 MeV."

Stanley M. Bunch, January 1965, Ph.D.

"Ranges of Alpha Particles in Gases."

Han-chuan Iiv Chang, January 1965, M.S.

"Scattering in a Spherical Potential."

R. I. Iackman, January 1965, M.S.

"Study of $\mathrm{F}^{19}\left(\mathrm{p}, \mathrm{He}^{3}\right) \mathrm{O}^{17}$ and $\mathrm{F}^{19}\left(\mathrm{p}, \mathrm{He}^{4}\right) \mathrm{O}^{16}$ Reactions and of the Elastic Scattering of $28 \mathrm{MeV}$ Protons by $\mathrm{Al}$, $\mathrm{Cu}$, $\mathrm{Ag}$, and $\mathrm{Au}$." Roger Dittman, June 1965, Ph.D.

"Elastic and Inelast1c Scattering of $31 \mathrm{MeV}$ Protons from $\mathrm{s}^{32}$." Hagop M. Hokhikian, June 1965, M.S.

"Effect of Antisymmetrization on Stripping Reactions Using Distorted Waves."

George L. Strobel, June 1965, Ph.D.

Articies

"A Critical Review of Experimental Stopping Power and Range Data." H. Bichsel, Publication 1133, studies in Penetration of Charged Particles in Matter (National Academy of Sclences-National Research Council, October 1964), p. 17.

"Scattering of High-Energy Deuterons from Carbon."

M. I. Rustgi, Nucl. Phys. 59, 460 (1964).

"New Short Iived Isomeric Levels in $\mathrm{Tl}^{201 \mathrm{~m}}$ and $\mathrm{Tb}^{153 \mathrm{~m}}$ "

V. T. Gritsyna and H. H. Forster, Nucl. Phys. 61, 129 (1965).

"Analytic Expressions for the Born Approximation to Certain Elements of the Reactance Matrix in e- $\mathrm{H}$ Scattering."

Bruce L. Scott, Phys. Rev. 137, A717 (1965).

"A Simple Analysis of the $\mathrm{Ii}^{6}(\mathrm{p}, \mathrm{pd}) \mathrm{He}^{4}$ Reaction."

D. W. Devins, H. H. Forster, and B. L. Scott, Rev. Mod. Phys. 37 , 396 (1965).

"The $D(p, 2 p) n$ Reaction at $31 \mathrm{MeV} . "$

S. M. Bunch, C. C. Kim, and H. H. Forster, Rev. Mod. Phys. 37 , $523(1965)$.

"Nuclear Optical Model Calculations."

M. A. Melkanoff, J. Raynal, and T. Sawada, Methods in Computational Physics (Academic Press, New York and London, 1965).

"Proton Total Reaction Cross Sections of Carbon from 16 to 28 MeV."

Motoji Q. Makino, Charles N. Waddell, and Robert M. Eisberg, Nucl. Phys. 68, 378 (1965). 


\section{Articles, continued}

"Coherent Knock out Amplitudes in Deuteron Stripping Reactions." George I. Strobel and Bruce I. Scott, Phys. Rev. In Press.

"The Elastic and Inelastic Scattering of $30.3 \mathrm{MeV}$ Protons by Si." Robert K. Cole, Roger R. Dittman, Charles N. Waddell, and

Harbhajan S. Sandhu, Nucl. Phys. Submitted 1965 for publication.

"Short Iived Isomeric Ievels in $\mathrm{Sn}^{115 \mathrm{~m}}$, $\mathrm{Sb}^{114 \mathrm{~m}}$, and $\mathrm{Yb}^{173 \mathrm{~m}}$." V. T. Gritsyna and H. H. Forster. To be published.

"Study of $\mathrm{Ii}^{7}$ Including $(p, d),(\mathrm{pT}),(\mathrm{ppd})$, and $(p, 2 p)$ Reactions at $30 \mathrm{MeV}$."

D. W. Devins, C. C. K1m, and H. H. Forster. To be published.

"Study of the $\mathrm{He}^{3}(\mathrm{p}, \mathrm{d}) 2 \mathrm{p}$ Final State Interaction:"

c. C. Kim and H. H. Forster. To be published. 